Article

\title{
Nestedness-Based Measurement of Evolutionarily Stable Equi- librium of Global Production System
}

\author{
Jiaqi Ren ${ }^{1}$, Yu Han ${ }^{1}$, Lizhi Xing ${ }^{1,}$ and Xianlei Dong ${ }^{2}$ \\ 1 College of Economics \& Management, Beijing University of Technology; renjq@emails.bjut.edu.cn (J-Q. R.); \\ koken@bjut.edu.cn (L-Z. X.); hanyu@bjut.edu.cn (Y. H.) \\ 2 Business School, Shandong Normal University; sddongxianlei@163.com \\ * Correspondence: koken@bjut.edu.cn
}

\begin{abstract}
Nested structure is a structural feature that is conducive to system stability formed by the co-evolution of species in mutualistic ecosystems, and reflects the ability of ecosystem stability to be restored to a stable state again after being destroyed. The co-opetition relationship and value flow between industrial sectors in the global value chain are similar to the mutualistic ecosystem, and the pattern of the global economic system is always changing in dynamic equilibrium. Nestedness theory is used in this article to define the generalist and specialist sectors in the global value chain to analyze the changes in the global supply pattern. Then we study the mechanism of the global economic system to reach a stable equilibrium and the role of different sectors in the steady of the economic system, so as to provide countermeasures for enhancing the stability of the global economic system. At the end of the article, the domestic trade network, export trade network and import trade network of each country are extracted, and an econometric model is designed to analyze how the microstructure of the production system affects a country's macroeconomic performance, thereby deriving the conclusion that the stability of the international trade network is crucial to a country's economic development.
\end{abstract}

Keywords: global value chain; global economic integration; nestedness; evolutionarily stable equilibrium

\section{Introduction}

Being relatively independent for a long period of time, the production systems of countries and regions in the world, however, as global economic integration improves, have gradually formed a global economic system through flourishing trade. And within sub-systems, the industrial value chains constitute the Global Value Chain (GVC) network, an interconnected and organic whole with specific functions. In such a network, the industrial sectors from each country form an interdependent and competitive community of shared destiny through the flow of capital, material and information, leading to the cross-country game relationship transcending geographical boundaries and ideologies. This resembles the mutually beneficial symbiosis among species in the natural ecosystem. Hence, industrial economics can bring in ecology theories to create a framework of systems science, giving rise to a new and explanatory research paradigm.

In theoretical ecology and evolutionary biology, nested structure refers to a structural measure of the overall stability in the ecosystems [1-3]. This concept has, in recent years, not only received attention in the field of natural ecosystem research, but also begun to be applied by sociologists and economists to analyze various phenomena related to human society. Considering its dual identity of being both the provider and consumer of intermediate goods, the industrial sector can be displayed through a bipartite graph in a way that resembles the co-occurrence relationship mutualistic ecosystem. In addition, the ecosystem and the global production system have some common grounds. For instance, the 
flow of energy between species and the flow of intermediate goods between industrial sectors both reflect the mutually beneficial symbiosis relationship produced through the competition and cooperation game, as shown in Figure 1. With the nested structure being identified among industrial sectors in the GVC network, nestedness can be applied to measure the topological stability of both the whole and local parts of the global industrial ecosystem.

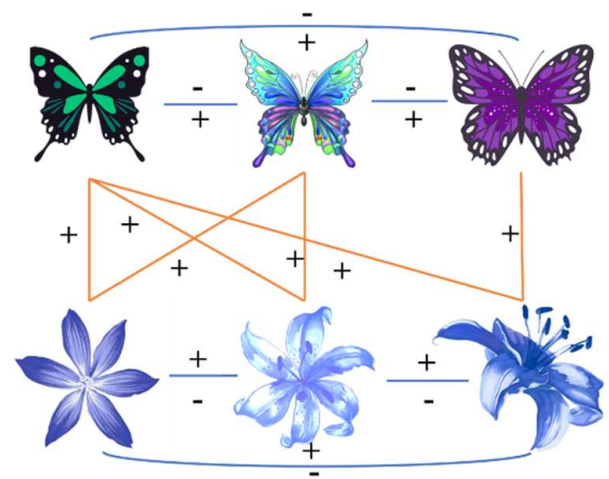

(a) Plant-Pollinator

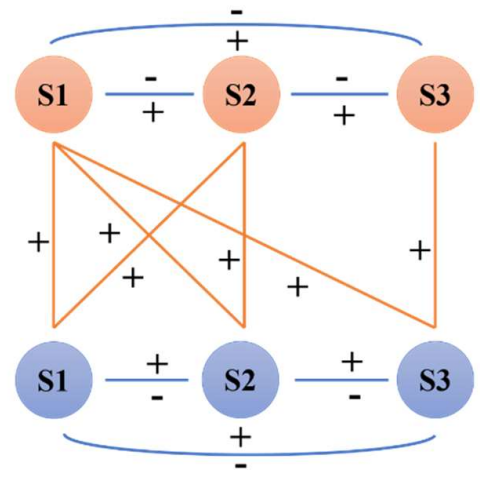

(b) Upstream Sector-Downstream Sector

Figure 1. Comparison between Mutualistic System and Global Production System. (a) there exists a mutually beneficial symbiosis relationship between plants and pollinators. In simple terms, pollinators pollinate plants to promote the formation of their fruits and take in the nutrients they need at the same time. Among pollinators, there is not only competition for plants but also collaboration to complete the process of collecting pollination, which will be beneficial to both sides as their population grows. (b) refers to the global production system where the orange circles represent the upstream sectors and the blue circles the downstream ones. The numerous upstream and downstream sectors on the GVC cooperate to complete the industrial division of labor, while the upstream ones not only compete for the same buyers but also collaborate to make true these buyers can get what they need in the production process.

This paper is organized as follows. In the first section, the application and development of nested structure theory in the field of ecology and economics are systematically introduced. In the second section, a GVC network is built based on the Multi-Region Input-Output (MRIO) database to embody the flow of intermediate goods between industrial sectors. In the third section, the mainstream algorithms for abstracting and measuring the nested structure are applied to quantify the nestedness of the global production system. In the fourth section, analyses on the divergence, trend, and stability are made to explain the complex relations between industrial sectors and the global production system they constitute, and then the economically evolutionary mechanism of this nested structure is proposed. In the fifth section, the econometric models are used to analyze the relations between the nestedness-based indicators and the level of economic development. Finally, some countermeasures are put forward for economies to achieve a much more stable and healthy state in the sixth section.

\section{Literature Review}

The nested structure, derived from theoretical ecology and evolutionary biology, is an important structural feature of complex networks. In 1957, Darlington mentioned this concept in his book Zoogeography, in which he noticed that species found on the farthest islands from land were also found on the nearest islands, and that the latter boasted better diversity of species. It was found that this spatial distribution of species displayed the nested feature [4]. Building on Darlington's discovery, in 1986, Patterson and Atmar formulated the precise concept of nestedness; i.e., in a fully nested network, the neighborhood of a node with lower node degree is a subset of the neighborhood of a node with higher node degree [5]. In 2003, Bascompte et al. analyzed 25 plant-pollinator networks 
and 27 plant-frugivore networks and found that most of the networks exhibited nested features [6]. The nested structure reflects the mutualistic relationship between species, in other words, the interaction between two species is beneficial to both. In a mutualistic network, specialist species tend to relate to generalist species who have higher adaptability to the environment, thus mitigating the risk of extinction. As a result, the ecological network would exhibit a certain degree of nestedness. It is found that the nested structure helps improve species diversity, and the stronger the nestedness, the stabler the network structure [1-3].

Inspired by the nested structure in ecological networks, scholars in socioeconomic networks began to devote themselves to the study of nestedness. As early as 1965, when studying the U.S. economic structure using intra-country input-output data, Leontief identified obvious nestedness of the U.S. industrial network [7]. In 2007, Soramäki et al. found that the bank transaction network based on the Fedwire Funds Services displayed a Core-Periphery Structure (CPS) [8]; in 2009, Saavedra et al. also identified nestedness in the manufacturer-contractor network of a New York garment factory [9]; in 2018, after 18 months of data collection in the Boulogne-sur-Mer Fish Market, Hernández et al. noticed certain extent of nestedness in the buyer-seller network [10]. In 2012, Andrea et al. proposed a Fitness-Complexity Algorithm (FCA) to study the complexity of economic systems and unexpectedly found that the algorithm was able to increase the degree of nestedness of the network [11]. In the same year, through the study of the country-product networks and the municipal-industrial networks, Bustos et al. confirmed that the nested structure is stable in terms of timeseries, which can be used to predict changes in industrial structure. It was concluded that industries/products far from highly nested areas would disappear/be halted and the industries/products missing from nested areas would appear in the future, providing insights into the spatial evolution of products at the national level [12]. In 2019, Alves et al. studied the nestedness of global production network with intercountry input-output data and discussed about the contribution of various countries and industries to nestedness, as well as the influence of nested structure in global economy [13]. In 2020, by comparing various network indicators of predatory networks and ecoindustrial park networks, Colton et al. found a positive correlation between the nestedness and periodicity of eco-industrial park networks, thus providing specific suggestions for the industrial layout and infrastructure construction in the park [14].

These researches, on the one hand, have made great contributions to the understanding and knowledge of the nested structure in economic systems and laid the groundwork for the future studies. On the other hand, most of the aforementioned studies on the nestedness in economic systems focused on the existence of nestedness and the description and application of its overall structural characteristics, leaving some gaps in the research on the ecological and functional roles of industries in the nested structure of GVC networks. From the perspective of bionics, GVC network can be recognized as a mutualistic ecosystem: upstream and downstream industrial sectors collaborate through resource exchanges and those in the same stream compete for resources due to the overlapping of industrial ecological niches [15]. This complex co-opetition relationship leads to the heterogeneous and nested characteristics of GVC networks [16].

\section{Data and Model}

In order to represent the nested structure formed by industrial sectors being both providers and consumers of intermediate goods on the GVC, it is necessary to build a GVC network that can reflect the co-opetition relationships of industrial sectors in each country.

\subsection{Data Sources and Structure}

Among the mainstream databases, the Eora Multi-Region Input-Output (MRIO) database of the University of Sydney covers the largest number of economies (189 countries/regions) and the longest period (1990-2015) and is suitable to be taken as modeling 
data to reflect economic phenomena involving a large number of global economies and to simulate their evolutionary trends. To make the nested structure more explicit and hierarchical, a simplified version of this database, Eora26, is chosen in this paper, i.e., to sort the industrial sectors in 189 countries/regions into 26 sectors which are further grouped into four sectoral categories, namely agriculture (sectors 1 and 2), mining (sector 3), manufacturing (sectors 4 to 14), and services (sectors 15 and 16), for ease of visualized analysis (Appendix A).

\subsection{Network Modeling}

As an emerging yet important research area, GVC accounting is mainly represented by teams of Timmer M.P., Koopman R., and Wang Z., who have made important breakthroughs in economic theories and statistical techniques, and contributed to researches at both national level and industrial level [17-19]. The important quantitative results they obtained have enriched the original GVC researches and cemented a theoretical basis for both the upcoming analysis and the formulation of relevant policies. They've also enabled the theoretical expansion to other GVC-related fields. Among all the achievements in GVC accounting, a set of preliminary accounting systems has been formed around value-added exports, which contains a series of indices reflecting industrial sectors' competitiveness and the participation degree on the GVC.

The global economic system, however, is a complex nonlinear emergence system, and the multiple emergences as its essential feature cannot be simply obtained by the linear addition of individualities. That is to say, the whole picture will be shadowed if only the individuals are analyzed. We should focus on the interrelationship and influence mechanism between individuals and the whole under the perspective of systems science.

The fact that industrial sectors on the GVC function as both upstream and downstream sectors can be displayed in a bipartite graph as in Figure 2(d). Based on the data of intermediate use in MRIO table, a Global Industrial Value Chain (Bipartite Graph) Network (GIVCNBG) is constructed in the form of a bipartite graph $G=(O, P, E, W)$. In $G$, all upstream industrial sectors form the set of object nodes $\mathrm{O}$, and all downstream industrial sectors form the set of participant nodes P; connected edges pointing from the upstream industrial sectors to the downstream industrial sectors, i.e., the flow direction of intermediate goods, form the set of edges $\mathrm{E}$ (the nodes' self-loop reflects that the industrial sectors transfer part of their own output into inputs, which are likewise merged into the set E); in competition with other $\mathrm{N}-1$ sectors as a consumption sector, downstream industry sector $\mathrm{i}$ obtains from its upstream industry sector $\mathrm{j}$ intermediate goods input, the amount of which is $w_{-}$ji ( $\mathrm{j}=\mathrm{i}$ indicates that the upstream and downstream are the same sector), constituting the weight set $\mathrm{W}$ in the form of a bipartite graph.

While the GIVCNBG model applies the weight set W to display the adjacency matrix, each row refers to the distribution of intermediate goods output from an upstream sector to several downstream sectors and each column the intermediate goods input obtained by a downstream sector from several upstream sectors. In spite of the same mechanism as the one-mode GIVCN model, a two-mode network is able to identify the underlying cooperative relationships between industrial sectors: cooperation between upstream sectors to promote the production of downstream sectors [20]. The authors believe that the flow of intermediate goods in production systems (expressed in the IO table as value flowing) is similar in nature to the flow of energy in ecosystems, and that both systems converge to a steady state after a complex game between subjects. As mentioned earlier, ecological studies have found that ecosystems in a steady state are characterized by nested structures and a more stable mutualistic relationship between species [1-3]. Such features can be further searched for in the topology of production systems. 

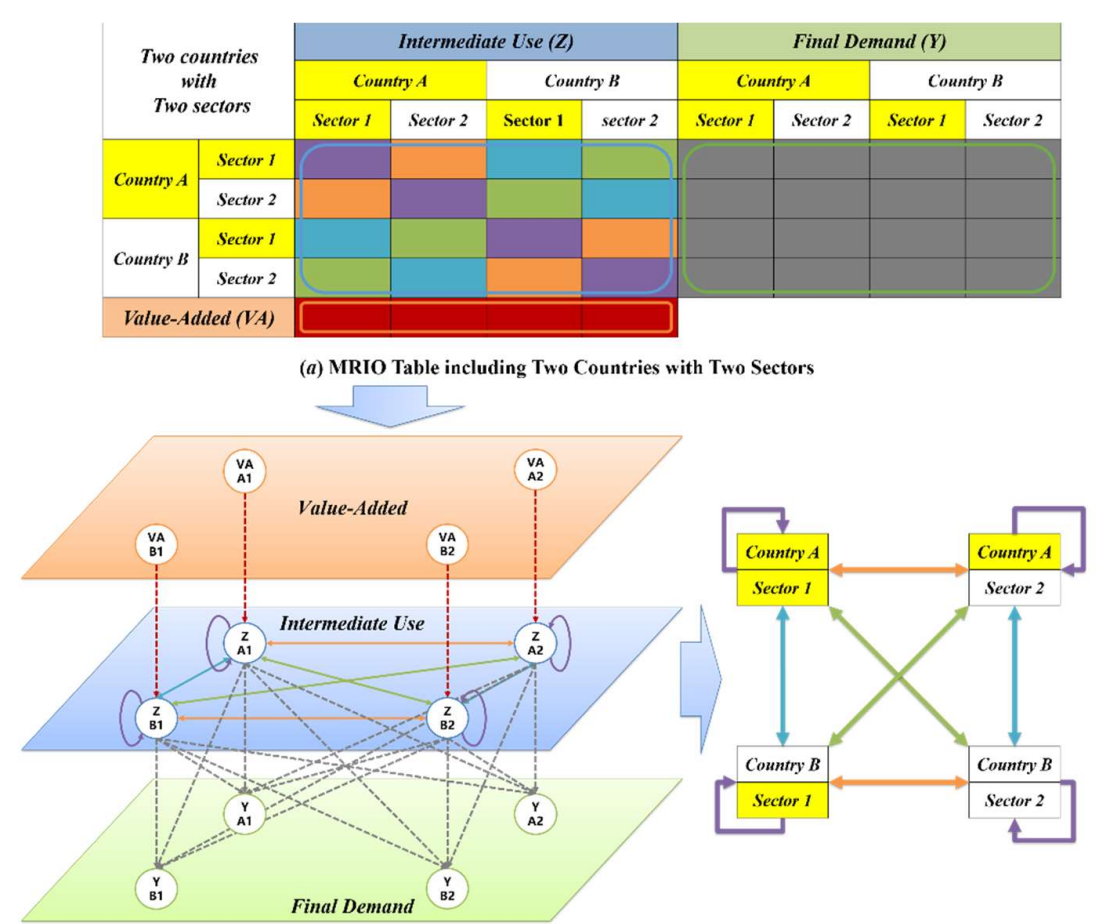

(b) Multi-Layer Structure of MRIO Tablc

(c) Onc-Mode MRIO Table

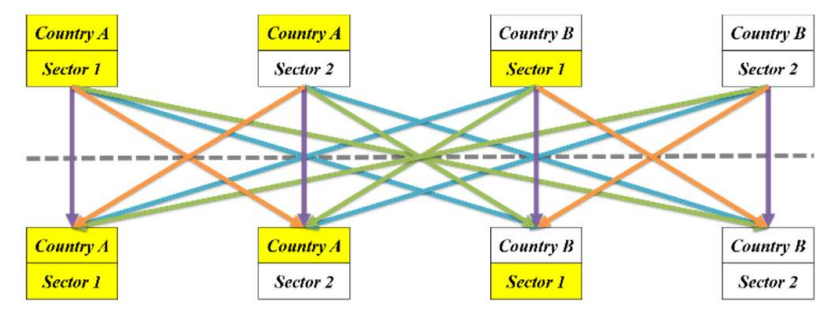

(d) Two-Mode MRIO Table

Figure 2. Relationship between MRIO Table and Network. Typica MRIO table includes three different areas, namely value-added, intermediate use and final demand. It is possible that the whole global economic system can be abstracted to a multi-layer network as shown in Figure 2 (b), which includes three layers: the value-added layer, the intermediate use Layer, and the final demand layer. The intermediate use layer can be further treated as a puzzle that is made of many singlelayer networks out of a multi-layer network, in which the nodes are the countries/regions, the layers are the industrial sectors, and links can be established from sellers to buyers within and across industrial sectors. If necessary, we can change the one-mode MRIO network into a two-mode network to separate the inner identity of each sector and prepare for the projection. In Figure 2 (d), the same sector distributes on the two sides of the dotted line, which means it belongs to both the upper stream and the lower stream. In other words, the upper stream sector in the MRIO table could be referred to as the object nodes in the bipartite graph, while the lower one as the participant nodes. Now, self-loop becomes a common edge between the two identities of this sector.

\subsection{Network Pruning}

The GIVCNBG is a very dense weighted network with highly heterogeneous material flows between each upstream sector and downstream sector and thus needs to be pruned in search of the backbone part before nested structure analysis. In this paper, a new heuristic algorithm-XIFA $[21,22]-$ is proposed, with the integration of the features of H-index [23], Pareto Principle and Disparity Filter [24]. Through XIFA, a special subgraph $\dot{G}=(O, P, E, E)$ is extracted from the GIVCNBG and is named as GIVCNBG-FE model (FE as in "Filtering Edges"). 
The GIVCNBG-FE model compresses the size of the edge set $E$ to a large extent, while preserving as much as possible the local heterogeneity embodied in the weight set $W$, allowing the backbone of GVC to be displayed. For example, after pruning the GIVCNBG-Eora26SC4-2015 model by XIFA, $|E|=8.95 \% \times|E|$, while $\sum w_{l j}=99.15 \% \times$ $\sum w_{i j}$, which means more than $90 \%$ of the deleted edges carry less than $1 \%$ of the network information, leaving less than $10 \%$ of the edges carrying more than $99 \%$. Given that the qualitative relationship of subjects is what is needed for nested structure analysis, the bipartite graph $\dot{G}=(O, P, E)$, with the weight information removed and all edges left being important, is sufficient to portray the nested structure of the network (For detailed algorithm information, refer to Appendix B).

\section{Nestedness Measurement}

The nested structure is determined by the distribution of edges in the network and can be influenced by the network connectivity. The higher the connectivity of the network, the more likely it is to exhibit nested characteristics [12]. In ecosystems, nested structure is established when ecological niches of different species adapt to each other and thus achieve dynamic equilibrium. It is a network structure characteristic formed by species adapting to the natural environment in pursuit of homeostasis. Nestedness in an ecological network is therefore a measure of the stability and sustainability of ecological environment. From the perspective of bionomics, there are many similarities between GVC network and ecological network in terms of topological characteristics; like species, the industrial sectors on the GVC form a complex association of mutual benefit and the trade and economic cycles between them make GVC an organic whole. Higher degree of nestedness of GVC network indicates a more mature industrial trade mechanism, a more regular and orderly industrial trade network, and the deeper integration between industries [11]. Hence, research on the nested structure of GVC networks has fundamental implications for the economic development of countries and even the world [25,26].

\subsection{Sorting Algorithms}

Prior to the analysis, the adjacency matrix needs to be first reordered to maximize the degree of network nestedness. Several algorithms for reordering the adjacency matrix are described below.

\subsubsection{SBD Algorithm}

Sorted by Degree, or SBD Algorithm, based on the concept of nestedness, sorts the adjacency matrix according to the degree of the network node (see Figure 3). It is prescribed in the nested structure that the neighborhood of lower-degree nodes is a subset of the neighborhood of higher-degree nodes, so the SBD algorithm basically rearranges the adjacency matrix's rows and columns in the descending order of the node's degree from top to bottom and from left to right respectively. In the rearranged network adjacency matrix, the topmost upstream sector boasts the largest number of downstream sectors, while the leftmost downstream sector boasts the largest number of the most upstream sectors.

\subsubsection{NTC Algorithm}

The Nestedness Temperature Calculator (NTC Algorithm) is a thermodynamicsbased algorithm proposed by Atmar, focusing on the degree of disorder of the measurement matrix [27]. The nested structure features ordered arrangement of nodes; therefore, the more disordered the adjacency matrix, the higher its temperature, and the lower the level of nestedness. NTC Algorithm uses a perfect order line to line out a perfect nested region at the top left of the adjacency matrix, and the unexpected absence of any element above the line and the unexpected appearance of any element below the line would result in an increase in the temperature of the adjacency matrix. 


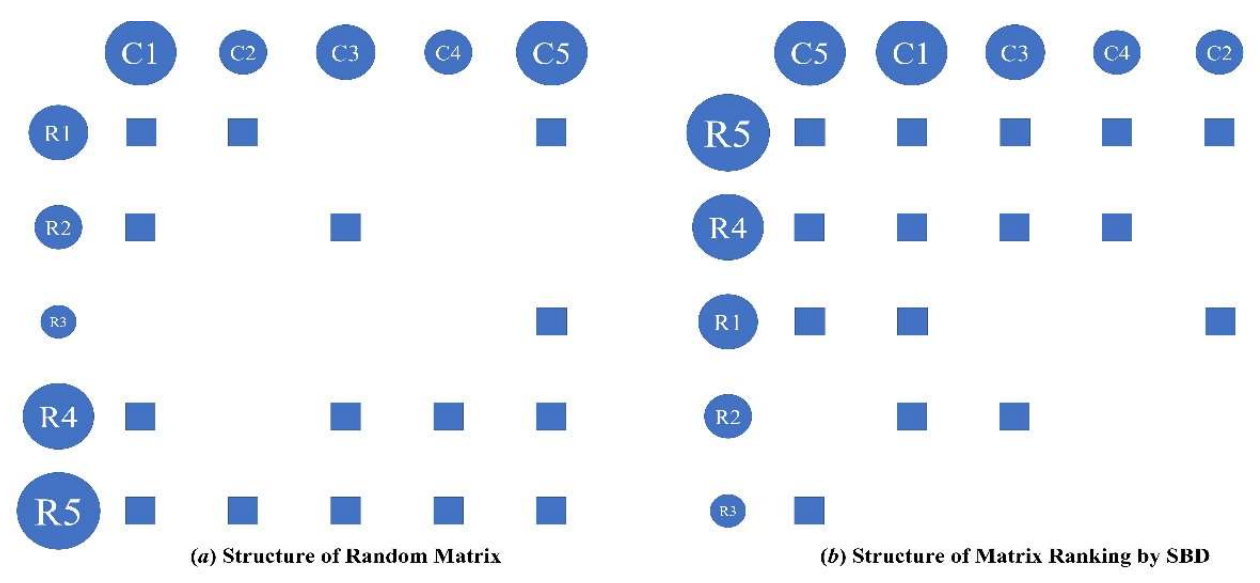

Figure 3. Sorting Adjacency Matrix Based on SBD Algorithm. This is a schematic diagram of the process of ordering nodes by degree. The solid blue circles represent each industrial sector, the rows represent the upstream industrial sectors, the columns represent the downstream industry sectors, the blue squares represent the existence of interdependence between upstream and downstream industries, and the size of the solid circles is proportional to the node's degree.

\subsubsection{BIN Algorithm}

BINMATNEST Algorithm (BIN Algorithm) was proposed by Rodri'guez-Girone's et al. based on the NTC algorithm in order to compensate for the shortcomings of NTC, e. $g$. the non-uniqueness of the perfect order line and the inadequacy of null model selection [28]. BIN algorithm is a genetic algorithm that minimizes the matrix temperature by rearranging the rows and columns. It first generates some alternative solutions and then lets the well-performing matrix to generate "offspring", thus iteratively filtering out the bestperforming one. Unlike the NTC algorithm, the BIN algorithm is able to screen out the optimal matrix with lower temperature. The matrix reaches the lowest temperature after reordering and is therefore more well-organized, with stabler connections between industrial sectors concentrated at the upper left corner. That being the case, the NTC algorithm will not be discussed further in this paper.

\subsubsection{FCA Algorithm}

Fitness-Complexity Algorithm (FCA Algorithm) applies a non-linear iterative method originally designed to measure economic complexity [9]. The mechanism is that the higher the fitness of a country, the higher its productive capacity or competitiveness; the higher the complexity of certain product, and thus the higher the productive capacity required from other countries producing that product. In the adjacency matrix of the country-product network, the rows represent countries and the columns the export products. After reordering the matrix in the descending order of fitness from top to bottom and product complexity from left to right, the new matrix will exhibit distinct nestedness. The algorithm therefore can be used to explore the maximum nestedness of a network.

\subsection{Nestedness Quantification}

Once a nested network structure is obtained, the nestedness of the network needs to be further quantified to compare the sorting algorithms. The NODF metric proposed by Almeida-Neto et al. is applied in this paper to calculate the nestedness of the network based on two basic properties: Decreasing Fill (DF) and Paired Overlap (PO) [29].

Given that a matrix has $m$ rows and $n$ columns, and $M T$ is the number of elements valued at 1 in any row or column. For any pair of rows $(i, j)(i<j)$, if $M T_{i}>M T_{j}$, then $D F_{i j}=100$, otherwise $D F_{i j}=0$; similarly, for any pair of columns $(k, l)(k<l)$, if $M T_{k}>$ $M T_{l}$, then $D F_{k l}=100$, otherwise $D F_{k l}=0$.

For any pair of rows $(i, j)(i<j), P O_{i j}$ refers to the percentage of 1 's in a given row $j$ that are located at identical column positions to the 1's observed in a row $i$; similarly, for any pair of columns $(k, l)(k<l), P O_{k l}$ refers to the percentage of 1 's in a given 
column $l$ that are located at identical row positions to those in a column $k$. Therefore, for any up-to-down row pair, or any left-to-right column pair, the degree of paired nestedness $\left(N_{\text {paired }}\right)$ can be expressed as follows:

$$
N_{\text {paired }}=\left\{\begin{aligned}
0, \text { if } D F_{\text {paired }} & =0 \\
P O, \text { if } D F_{\text {paired }} & =100
\end{aligned}\right.
$$

There are $m(m-1) / 2$ row pairs in row $m$, and $n(n-1) / 2$ column pairs in column $n$. Thus, the nestedness of the entire network can be calculated by "averaging all paired values of rows and columns":

$$
N O D F=\frac{\sum N_{\text {paired }}}{\left[\frac{m(m-1)}{2}\right]+\left[\frac{n(n-1)}{2}\right]}
$$

The nestedness can be quantified by calculating the NODF value of each matrix, so as to compare various sorting algorithms for nestedness. The NODF values range from 0 to 100 , with $N O D F=0$ indicating non-nested network structure and $N O D F=100$ indicating a fully nested network structure.

This study applies the GIVCNBG-FE-Eora26SC4 model to calculate the nestedness of the GVC network after network pruning and nested structure sorting at intervals of five years, and compare the sorting results of SBD, BIN and FCA algorithms and their NODF metrics, as shown in Figure 4.

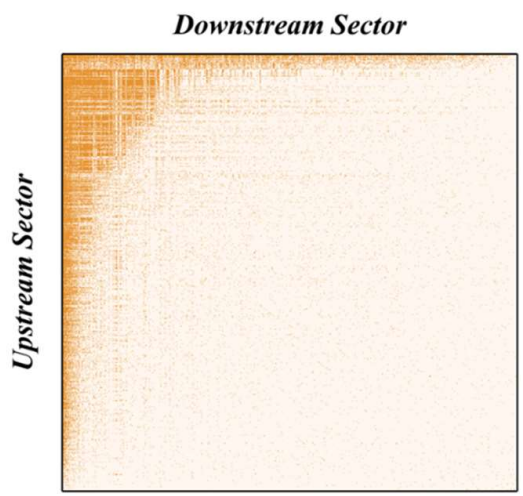

(a) Adjacency Matrix Ranking by SBD

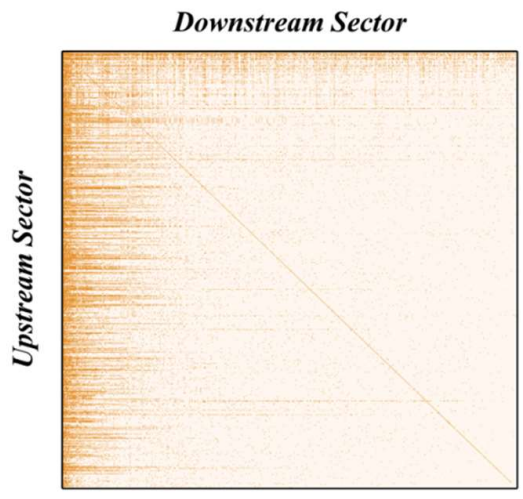

(c) Adjacency Matrix Ranking by FCA

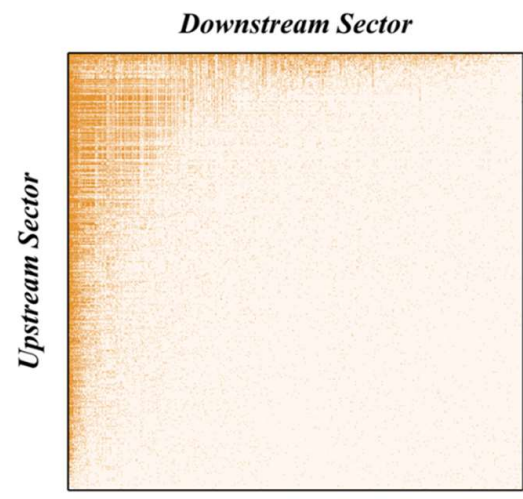

(b) Adjacency Matrix Ranking by BIN

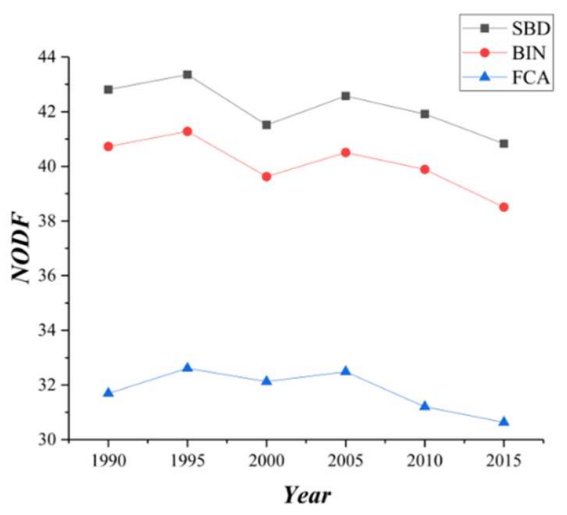

(d) NODF of Three Algorithms

Figure 4. Sorting Adjacency Matrix of GVC Network Based on Three Algorithms and Its Corresponding NODF Variation Trend. (a), (b), and (c) are the adjacency matrix ranking results obtained according to the SBD, BIN, and FCA algorithms, respectively. Where the vertical axis represents the upstream sector and the horizontal axis represents the downstream sector, and each non-empty position reflects the transfer of intermediate products from the upstream sector to the downstream sector. This input-output relationship between industrial sectors resembles predation in an ecosystem: the upstream sector, as the provider of energy (products and services), can be regarded as the prey; the downstream sector, as the consumer of energy (products and services), can be regarded as the predator. And each industry sector plays dual role in the industrial ecosystem. 
The SBD algorithm sorts adjacency matrix in the way that most of the non-zero elements are clustered at the upper left corner. The results obtained by the BIN algorithm resemble that of the SBD algorithm, with the upper left corner being sparser. The results obtained by the FCA algorithm are computationally weaker than the other two algorithms. Given the above analysis (see Figure 4(d)), the SBD algorithm is thus used in this paper to sort the nested structure of the network adjacency matrix. The overall smooth NODF values indicate temporal stability of the nested structure of the network - that is to say, the topology of the GVC network does not change drastically during a normal economic cycle.

\section{Results}

Globalization is both an opportunity and a threat for the economic development of each country. On the one hand, the industrial sectors of each country have their comparative advantages, thus forming a relatively stable international industrial division of labor; on the other hand, they also fiercely compete in the global market, seeking for a place on the GVC. It is under the impetus of both cooperation and competition that the global economic system evolves and shows nested structural characteristics in the process of convergence to homeostasis.

\subsection{Divergence Analysis}

If the economic system is compared to an ecosystem, the generalist feature of an industrial sector on the GVC can be measured by the number of important input-output relationships they establish with other sectors. In this paper, in the nested network based on the SBD algorithm, the larger-degree industrial sectors are defined as Generalist Industrial Sector, featuring higher involvement on the GVC, widely distributed outputs/inputs, and broader industrial ecological niche; in the opposite would be the Specialist Industrial Sector. Viewed by rows, the nodes in the upper part of the nested area have higher outdegree and stronger supply-side generalist degree, while those in the lower part have lower outdegree and weaker supply-side generalist degree. Viewed by columns, the nodes on the left side have higher indegree and stronger demand-side generalist degree, while those on the right side have lower indegree and weaker demand-side generalist degree.

Due to the vertical specialization on the GVC, product manufacturing and its related services exists through all stages of the global production process. Each country takes advantage of its own and others' comparative advantages in technology, capital and/or labor, jointly shaping the main structure of GVC. As a result, the manufacturing and service are sectors with a high degree of external dependence and high generalist degree. In contrast, agriculture and mining, as basic industries affecting a limited number of sectors on the value chain, mainly trade with related domestic industrial sectors for self-sufficiency or establish international trade channels with the manufacturing sectors of a few developed economies. In short, most agriculture and mining sectors have low involvement on the GVC, and consequently low generalist degree. To further analyze the nestedness of GVC, this paper zooms in on the local networks consisting of the top twenty and bottom twenty industrial sectors on the supply and demand sides, as shown in Figure 5. The comparison reveals significant differences in the generalist degree of industrial sectors in developed and developing countries.

Region A on the top left shows the input-output relationship between the upstream and downstream GVC sectors. This value network consisting of manufacturing and service industries in advanced economies is very dense, indicating that intense competition occurs because of overlapping ecological niches. The NODF value of Region A is 76.165, due to the empty elements of the upper triangle and the non-empty elements of the lower triangle, which indicate the insufficient collaboration and excessive competition among these generalist sectors and hence negatively affect the stability of the industrial structure. 
Region B in the top right shows the input-output relationship between the upstream generalist sectors and the downstream specialist sectors. It is found that Japan's service industry is a generalist sector in the upstream, whose trade in services exports to most countries on the GVC, while this sector has very low generalist degree in the downstream. On the one hand, Japan's service industry is highly developed and mainly in the form of outsourcing. Along with the progress of economic globalization and division of labor, Japan's service industry penetrates into all links of the GVC. On the other hand, Japan's market remains relatively closed. Since the World War II, Japan's industrial structure has been continuously upgraded, and various industries, especially the service industry, have reached a fairly mature stage and become the dominant industry in Japan. Other countries are difficult to access because of the high trade barriers.

From the bottom two regions, the agriculture and mining industries in underdeveloped countries/regions have lower generalist degree on the GVC-except for achieving self-sufficiency (see Region D), they only open international trade channels with the manufacturing sectors of a few developed economies (see Region C). Firstly, as the multilateral trading system is frequently challenged by unilateralism, agriculture often passively becomes an important bargaining chip for balancing bilateral economic and trade relations, together with the presence of invisible barriers to agricultural trade, posing obstacles to the globalization process of the agricultural sector. On the other hand, since the globalization of the mining industry depends on resource endowment and geographical factors, only a few countries are able to achieve significant exports of mineral resources, upon which most other countries have to rely.
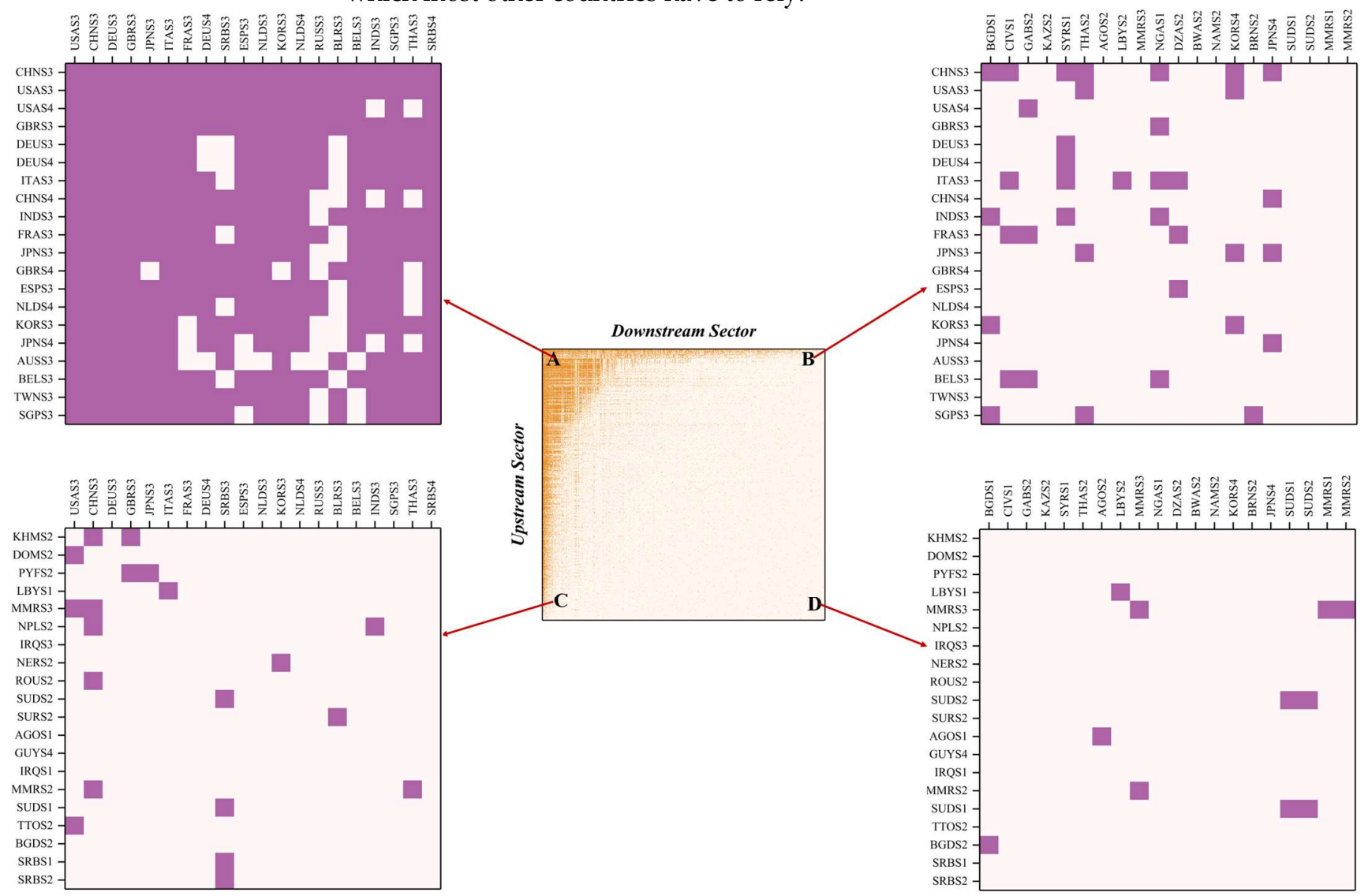

Figure 5. Topology of Different Regions after Sorting the Adjacency Matrix of GVC Network Based on SBD Algorithm.

\subsection{Trend Analysis}

In order to observe the dynamic trend, this paper puts together the top twenty industrial sectors in terms of generalist degree in the upstream and downstream sectors in each statistical window, as shown in Figure 6. Overall, the major generalist sectors on the GVC 
did not change significantly between 1990 and 2015, with the absolute generalist value fluctuating in a small scale. In particular, the manufacturing and service sectors of the U.S. and Germany in the export sectors, and the manufacturing industries of both countries in the import sectors, have always maintained a high degree of generalist, deeply integrating into all parts of the global economic cycle. However, some variation trends also deserve more attention.

First, the export trade reflected by the upstream sector's generalist degree and the import trade reflected by the downstream sector's generalist degree tend to wax and wane. In particular, with the scaling-up influence exerted by China's manufacturing export trade, the generalist degree distribution of the upstream manufacturing sector has evolved from a "U.S.-Germany-Japan" tripolar pattern to a "China-U.S.-Germany" one [30]. At the same time, China's exports of trade in service have begun to narrow the gap with developed countries and surpassed Japan.

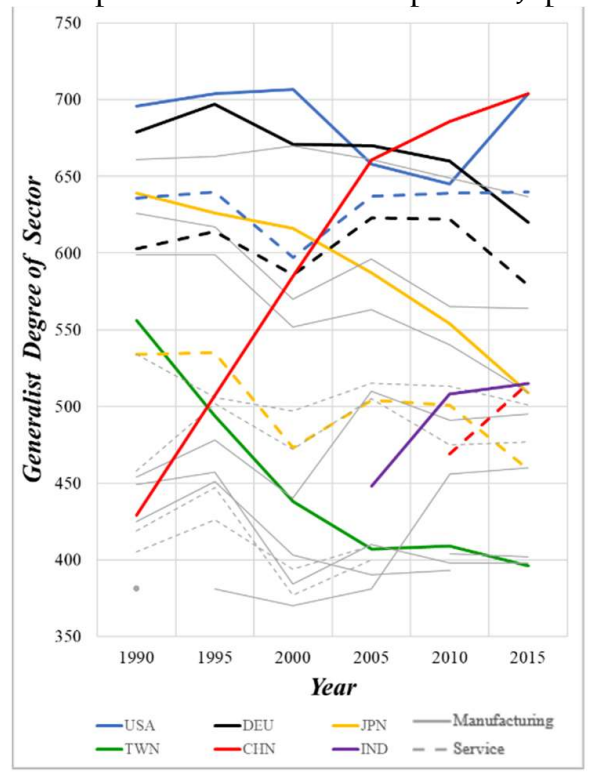

(a) Variation Trend of Upstream Generalist Sectors

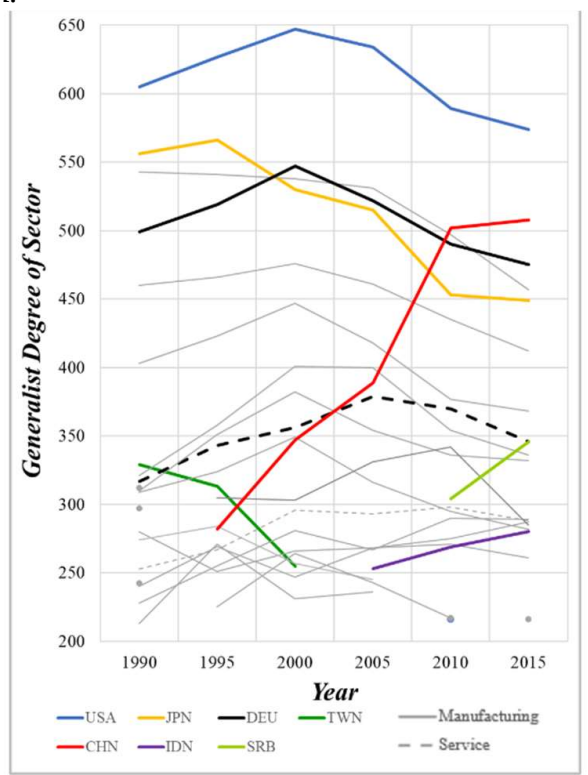

(b) Variation Trend of Downstream Generalist Sectors

Figure 6. Generalist Degree Variation Trends of the Upstream and Downstream Industrial Sectors.

Second, the rise of manufacturing in China's mainland and India has brought impact to Taiwan. As one of the once "Four Asian Dragons", Taiwan used to be a supply chain hub in Asia, except for Germany and Japan for western countries. However, with the advent of dividends of China's reform and opening up, productive enterprises in Taiwan began to move to China's mainland and overseas, leading to the significantly shrunk influence of Taiwan's manufacturing industry on the GVC. Besides, in order to accelerate the development of the manufacturing industry, the Indian government has introduced a batch of relevant measures to stimulate investment and ease market access for foreign investment. Due to the blockade and restrictions imposed by the European and American markets on the Chinese market, a huge market like India is taken as the preferred place for partial industrial transfer, which provides favorable conditions for the development of manufacturing industry in India [31].

Finally, Serbia has become a new "European factory" by virtue of its unique location, and started to play an important role in the import and export trade of manufacturing industry in recent years. Located at the junction of the East and the West, Serbia is an important hub connecting the major corridors of Europe and Asia, and boasts strong connectivity, for it has signed free trade agreements with the European Union and Central and Eastern Europe, and enjoys the most-favored-nation treatment of the U.S. With the progress of the Belt and Road Initiative, Chinese enterprises are building infrastructure in Serbia, creating a favorable environment for the development of Serbian manufacturing 
industry, thus making Serbia an important intermediate goods processing link on the GVC.

\subsection{Stability Analysis}

In order to investigate the influence of generalist and specialist sectors on the nestedness of GVC network, two experiments are designed to examine the influence of a certain sector and the cumulative influence of multiple sectors respectively, and the results are shown in Figures 7 and 8.

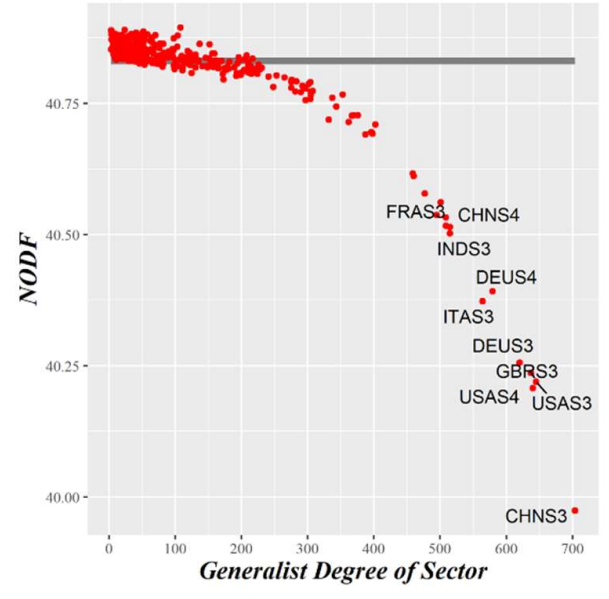

(a) Remove the Upstream Sectors Respectively

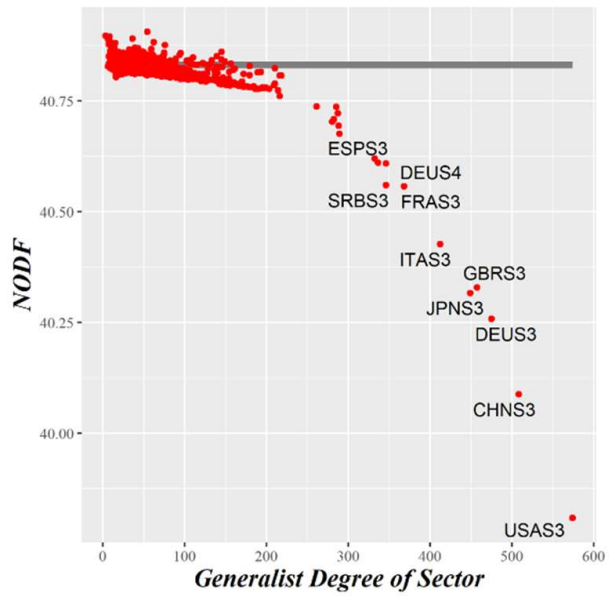

(b) Remove the Downstream Sectors Respectively

Figure 7. The NODF of Removing a Certain Industrial Sector of the GVC Network. The horizontal gray lines represent the NODF of the nested network sorted by the SBD algorithm, and the red scatter points represent the correspondence between the generalist degree after removing a certain industrial sector (the size of the outdegree or indegree) and the new NODF of the nested network.

As shown in Figure 7, after removing a generalist sector, the NODF of the nested network significantly decreases, indicating that the higher the industry sector's generalist degree, the more positive its effect on maintaining the stability of the GVC network. In contrast, after removing a specialist sector, the NODF slightly increases, which means that industrial sector with lower degree of generalist would weaken the stability of the GVC network. With the deepening of globalization, these industrial sectors will entail the risk of being marginalized or even eliminated if they do not actively participate in international competition and cooperation.

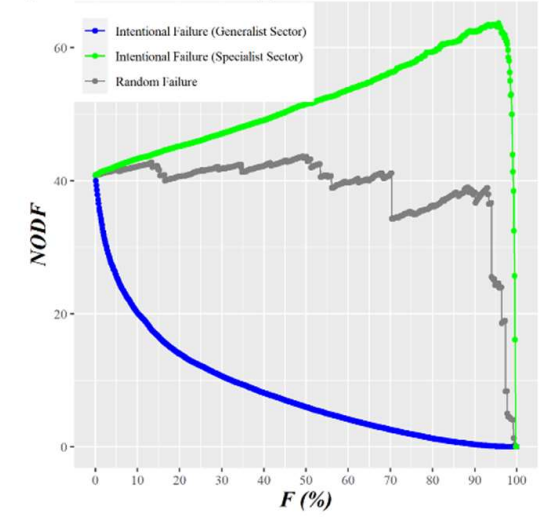

(a) Remove the Upstream Sectors Proportionally

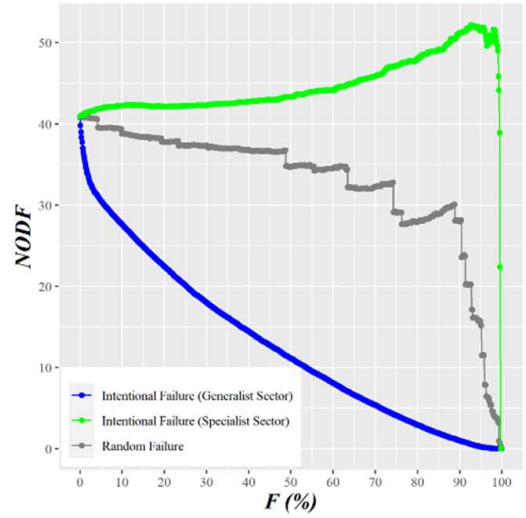

(b) Remove the Downstream Sectors Proportionally

Figure 8. The NODF of Proportionally Removing Industry Sectors of the GVC Network. The gray lines represent the variation in the value of network nestedness after randomly removing a certain proportion of industrial sectors from the aligned adjacency matrix; the blue lines represent the variation in the value of network nestedness after removing industrial sectors from the aligned adjacency matrix in the descending order of generalist degree; the green lines represent the variation in 
the value of network nestedness after removing industrial sectors from the aligned adjacency matrix in the descending order of specialist.

Figure 8 further confirms the above findings. After removing a small proportion of industrial sectors with the highest generalist degree, the NODF of the nested network fall drastically, i.e., the stability of the GVC network deteriorates rapidly, indicating that a few generalist sectors are important hubs to maintain the functioning of the GVC. In contrast, when the industrial sectors with the lowest generalist degree are removed, NODF display an increasing trend which does not start to decline until only $10 \%$ of the industry sectors are left. This reinforces the importance of the generalist sectors to the stability of the GVC network. In addition, by comparison of Figure 8 (a) and 8 (b), it can be seen that given the same proportion of removed generalist sectors (e. g. 10\%), the removal of upstream sectors would exert greater negative impact on the nestedness of the GVC network than that of downstream sectors. In other words, the global demand network of intermediate goods (consisting of downstream sectors) is sturdier than the supply network (consisting of upstream sectors). In light of this, when the global economy faces systematic risks, in order to cope with the resulting pressure or even disruptions of supply chains and reduce economic dependence on external resources, many countries have explored alternatives for supply chain management and import dependency, by moving their supply chains to countries less affected by the pandemic, or reshoring some of the production back from overseas, thus accelerating industrialization process.

\subsection{Evolutionary Mechanism}

Dependency Theory, also known as core-periphery theory, established on the world trade pattern and the resulting unequal international division of labor, explains the differences between developed and developing economies. The theory holds that developed countries gather at the center of the world economic system, while developing countries scatter at the periphery; the countries at the center transfer the production of primary products to peripheral countries through capital import and transnational corporations, exploiting the peripheral countries' cheap labor resources to develop labor-intensive industries and thus optimizing their own industrial structure. Being subject to the external constraints of the central countries, peripheral countries form dependence on the central countries; the surplus value keeps flowing from the periphery to the center, thus leading to the rich countries getting richer and the poor countries getting poorer [32-35]. For example, after the World War II, the Asian, African and, especially, Latin American countries did not embark on the road to affluence after their attainment of independence, but instead, became even more dependent on and formed the neo-colonialist industrial affiliation with the economy of capitalist countries in Europe and North America. Given that, the advocates of the dependency theory call for trade protection and import substitution in the peripheral countries and, with a strong nationalist tendency, encourage them to develop their own industries. However, this theory puts the peripheral countries in a passive position and attributes their economic distress on external factors, taking no consideration of the drawbacks in their domestic economic structures, which is to some extent pessimistic and biased.

In spite of the similar nested structures of the mutual benefit ecosystem and the global economic system at the topological level, their formation mechanisms are not identical. Species in the mutual benefit ecosystem enhance their ecological benefits by continuously adjusting their interactions with other species, and the nested structure evolves through the species' dynamic game play and active adaptation to the environment. On the other hand, the driving force behind the formation of the core-periphery model of the global economic system lies in the international division of labor based on the countries' comparative advantages, and therefore features historical inevitability. However, from the perspective of dynamic development, peripheral countries are not always stuck in a position of being exploited and unable to develop their economies. On the contrary, the industrial transfer of the center countries creates opportunities for the peripheral countries to make full of the capital and technology of developed countries to promote their 
own industrial development and technological innovation, thereby achieving the socalled "corner overtaking". With the increased depth and breadth of the GVC, by transferring a large number of industrial production processes to developing countries, developed countries have completed the transition from a production-based society to a consumption-based society and need to rely on the supply of goods from developing countries. This has inevitably led to the emergence of Industrial Hollowing-Out in some developed countries, increasing their dependency on the developing countries as the world factories. Figure 9 briefly shows the movement of peripheral countries to the center of the industrial landscape, which is also the formation process of the nested structure of the global production network. From the perspective of evolutionarily economics, the continuously flattened world is derived by the evolutionarily stable equilibrium of global production system.

Of course, the heterogeneity of economic development engendered by the international division of labor is still prevalent, and even increasingly serious. Even if the peripheral countries in the global industrial pattern achieve their economic growth targets, they are still at the end of high-tech diffusion, lacking core technologies and high value-added products, and are often subject to economic sanctions and technological blockade by the central countries. In other words, the dependence of peripheral countries on the center countries is much stronger than that in the reverse. Developing countries therefore need to face up to the gap with developed countries in various aspects, transform economic growth mode, so as to become the beneficiaries of economic globalization rather than just the contributors.

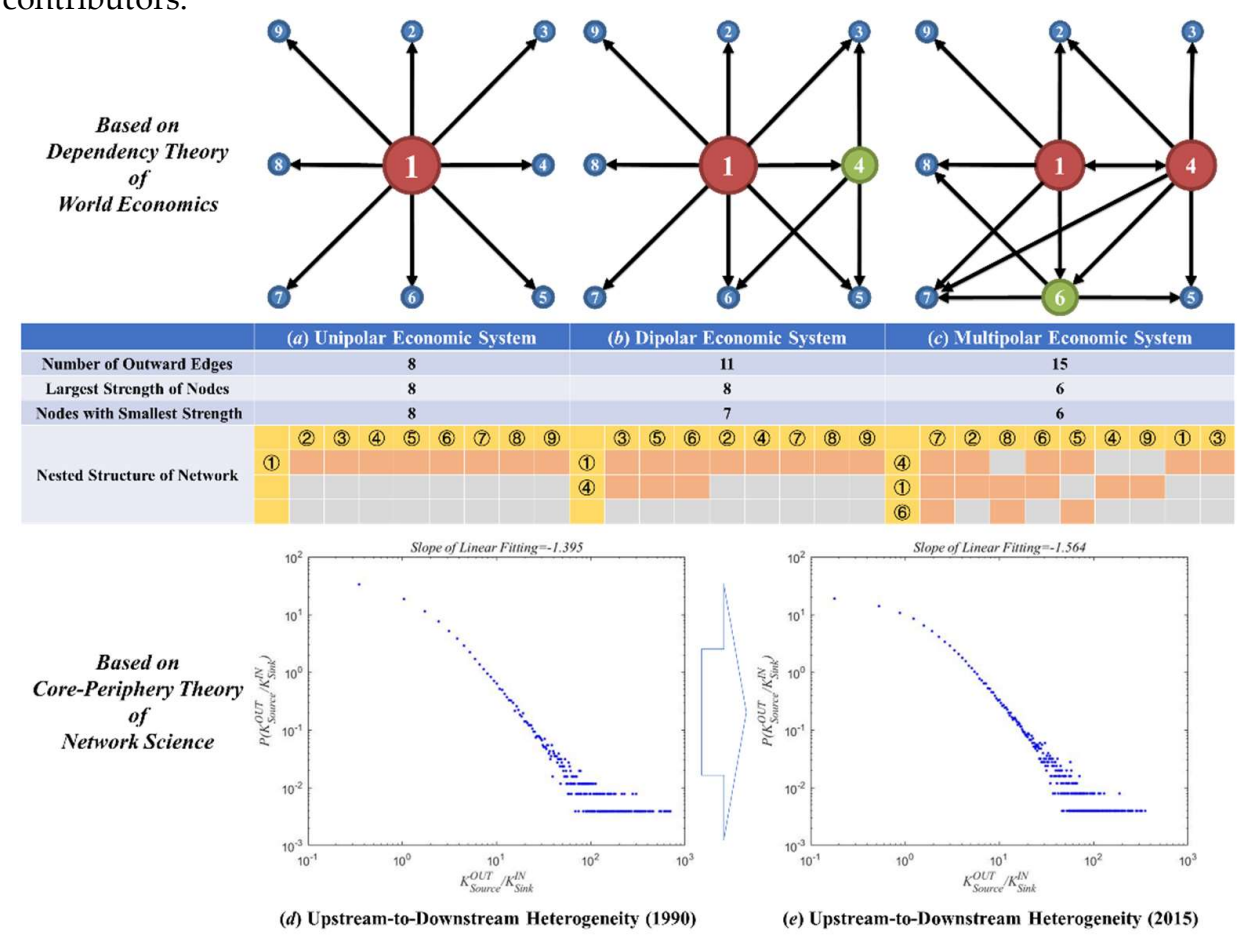

Figure 9. The Formation Process of Nested Structure of the GVC Network. The orange circle 1 in (a) represents the developed countries initially at the center of the world economic system, while the yellow circles are the developing countries at the periphery, and the size of the circles reflects the degree of centrality of the countries; (b) and (c) indicate the gradual migration process of peripheral country 4 and peripheral country 6 to the central position, respectively. Besides, the ratio of out-degree of upstream sectors to in-degree of downstream ones is designed to reflect the heterogeneity of development level of economies. Accordingly, the absolute value of slope of linear fitting increasing in (d) and (e) means our world is flattened by the economic integration.

\section{Econometric Analysis}


After analyzing the generalist degree and ecological functions of industrial sectors based on the nested structure theory, it is found that the generalist degree of a country's industrial sectors is closely related to its economic status and productive capacity. So, the focus of the following section is going to be whether a country's economic condition is affected by the nested structure of the GVC network, or in other words, how a country's macroeconomic performance is related to the microstructure of the GVC network.

\subsection{Correlation between Variables}

Considering that a country's macroeconomic performance is affected by both domestic and international trade cycles, this paper designs three NODF-based indicators to measure the nestedness of the local network in terms of economies. Firstly, DTN-NODF measures the nestedness of Home Trade Network, which consists of trade activities of intermediate products between industrial sectors within a country. Secondly, ETN-NODF measures the nestedness of Export Trade Network, which is formed when industrial sectors of a country, as upstream sectors (supply side), trades intermediate products with other countries. Thirdly, ITN-NODF measures the nestedness of the Import Trade Network formed when a country's industry, as a downstream sector (demand side), trades intermediate goods with other countries. In terms of macroeconomic performance, this paper uses Gross Domestic Product (GDP) data provided by the World Bank.

Based on the GIVCNBG-FE-Eora26 model, the correlation diagrams of DTN-NODF, ETN-NODF, ITN-NODF and GDP are plotted at intervals of five years (as shown in Figure 9) to observe the connection between the industrial and trade structures of economies and macroeconomic performance.

Based on three sets of correlation analysis in Figure 10, the following three conclusions are reached.

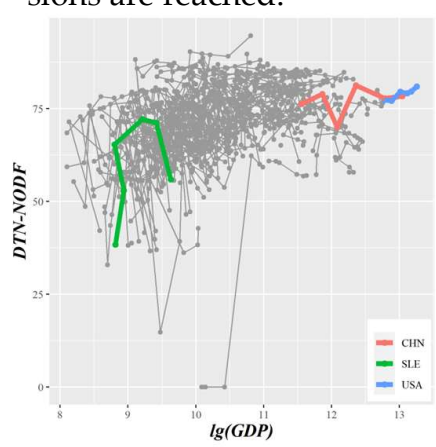

(a) DTN-NODF and GDP

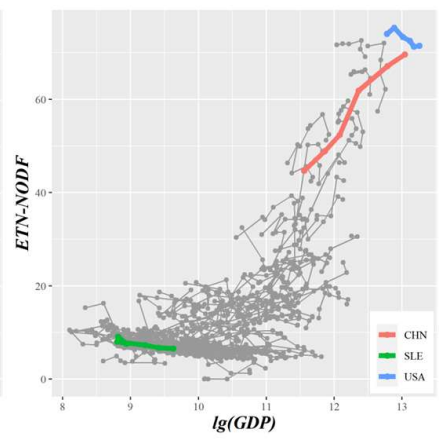

(b) ETN-NODF and GDP

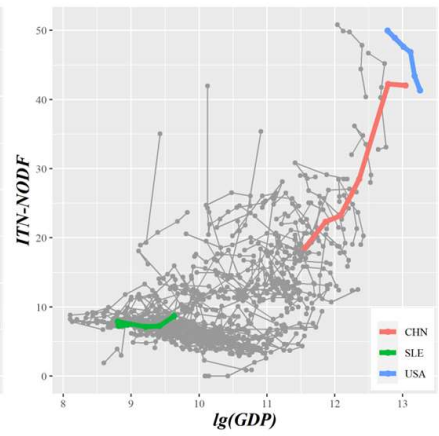

(c) ITN-NODF and GDP

Figure 10. Correlation of DTN-NODF, ETN-NODF, ITN-NODF and GDP. In order to compare the relationship between a country's economic status and the network nestedness, three countries with large differences in GDP are selected, with red representing China, blue the United States, and green Sierra Leone.

Data source: World Bank - https://data.worldbank.org.cn/indicator

First, in all countries, the values of DTN-NODF are larger (mostly between 50 and 80 ), and the values of ETN-NODF and ITN-NODF are smaller (mostly between 0 and 20), which indicates that in the context of international division of labor, compared with international trade networks, most countries have relatively mature domestic trade networks, in which domestic industrial sectors can also form synergy. Hence, it is much less difficult and risky to form a domestic trade cycle of industrial chain, moving the original countryto-country trade to province-to-province and city-to-city economic cycle. Certainly, the premise is that the country's domestic market is sufficiently huge and the industrial system complete.

Second, be it a domestic trade network or an international trade network, economies with better macroeconomic performance usually have higher the nestedness, which indicates that with the relatively mature trade mechanisms, their industrial layout has brought them with economic benefits and avoided risks. Hence, domestic and international market 
are equally important for a country's economic development. How to better connect and better utilize the domestic and international markets will be the key for countries to gain new advantage in international cooperation and competition.

Third, the ETN-NODF and ITN-NODF of the United States show a negative correlation with its GDP. In recent years, the U.S. has benefited greatly from globalization thanks to its deep involvement in the international cycle. The U.S. has integrated a large amount of capital into the highly lucrative consumption side, and shifted low-end manufacturing to countries with cheap labor costs, thus leading to the advent of Manufacturing Hollowing-Out. Combined with industrial shocks from many developed (e. g. Germany and Japan) and developing countries (e. g. China), the international trade cycle does not seem to be contributing to the macroeconomic performance of the U.S. as expected. Such industrial layout of the U.S. undermines its stability when encountering the rare but sever systematic risk. For instance, American government cannot get enough prevention and control supplies at the beginning of the pandemic.

\subsection{Regression Model}

To describe the quantitative relationship between GDP and the nestedness indicators accurately, this paper applies regression analysis on these four variables. First, a mixed effect regression model was established by taking GDP of each country as the dependent variable and DTN-NODF, ETN-NODF and ITN-NODF as the independent variables, as shown in Table 1.

The correlation coefficients between the three independent variables are examined to check the existence of multicollinearity problems in the above model, so as to avoid spurious regression and ensure the validity of the model. The results show that the two variables, ETN-NODF and ITN-NODF, are significantly correlated, with correlation coefficients as high as 0.8608 (0.2631 for DTN-NODF and ETN-NODF, and 0.3289 for DTNNODF and ITN-NODF).

Table 1. Results of the Mixed Effect Regression Model.

\begin{tabular}{cccccc}
\hline Variables & Coef. & Robust Std. Err & $\mathbf{t}$ & $\mathbf{P}$ & $\mathbf{9 5 \%}$ Confidence Interval \\
\hline DTN-NODF & -9.49 & 2.64 & -3.60 & 0.000 & {$[-14.67,-4.32]$} \\
ETN-NODF & 44.27 & 3.88 & 11.40 & 0.000 & {$[36.65,51.90]$} \\
ITN-NODF & 21.03 & 6.88 & 3.06 & 0.002 & {$[7.54,34.52]$} \\
Intercept Term & 71.97 & 180.36 & 0.40 & 0.690 & {$[-281.95,425.89]$} \\
R2 (adjusted) & 0.411 & & Root MSE & 867.68 & \\
\hline
\end{tabular}

Referring to previous studies, Principal Component Analysis (PCA) is performed in this paper between P-NODF and C-NODF to investigate the components that constitute their covariance and ensure the orthogonality of the independent variables, avoiding multicollinearity problems in the following regression [36]. The ranked components with their loadings are listed in Table 2, turning out that both the KMO test and the SMC test confirm the correctness of PCA. The first principal components of PCA results are retained in this paper. Meanwhile, as shown in Appendix Table V, we used a Ridge regression to find the penalization term and found that the coefficients and conclusions are robust. We also provided the results of fixed effects model (FE), random effects model (RE) and least square dummy variable model (LSDV). As shown in Appendix Table VI-VIII, we concluded that the pooled regression (i.e. Mixed Effect Regression Model) with PCA is the optimal solution (Appendix C).

Table 2. Principal Component Analysis of DTN-NODF and ITN-NODF.

Component Eigenvalue Difference Proportion Cumulative KMO SMC




\begin{tabular}{lccccrc} 
ETN-NODF & 233.326 & 220.745 & 0.9488 & 0.9488 & 0.9999 & 0.7410 \\
ITN-NODF & 12.581 & - & 0.0512 & 1.0000 & 0.9999 & 0.7410 \\
\hline
\end{tabular}

As shown in Table 3 , the model exhibits a relatively good fit with a large $\mathrm{R}^{\wedge} 2$ and all the independent variables (DTN-NODF and Component variable) pass the p-value test at the significance level of 0.01 .

Table 3. Results of Mixed Effect Regression Model after PCA.

\begin{tabular}{cccccc}
\hline Variables & Coef. & Robust Std. Err & $\mathbf{t}$ & $\mathbf{P}$ & $\mathbf{9 5 \%}$ Confidence Interval \\
\hline DTN-NODF & -9.63 & 2.60 & -3.71 & 0.000 & {$[-14.72,-4.54]$} \\
Comp. & 48.99 & 1.83 & 26.74 & 0.000 & {$[45.39,52.58]$} \\
Intercept Term & 74.09 & 180.14 & 0.41 & 0.681 & {$[-279.40,427.57]$} \\
$\mathbf{R}^{2}$ (adjusted) & 0.411 & & Root MSE & 867.3 & \\
\hline
\end{tabular}

Notes: Comp. $=0.8824$ ETN-NODF +0.4705 ITN-NODF

From the above results, DTN-NODF display a weak negative correlation with GDP. It is believed that an excessively nested domestic trade network may hinder a country's economic development. Although a highly nested industrial layout can enhance the stability of the production system, it can also bring about problems such as lack of effective competition, path dependence in innovation, and blocked channels for international cooperation, thereby hampering the country's macroeconomic performance. On the other hand, ETN-NODF and ITN-NODF show a significant positive correlation with GDP. This can be attributed to the fact that for those who actively participates in the international trade cycle, they can complement each other by their own advantages and efficiently leverage resources in the international market, which leads to domestic socio-economic development.

Besides, the regression model indicates that the positive effect of ETN-NODF on GDP is greater than that of ITN-NODF, to a degree of about two times. This is also a self-evident phenomenon. Larger ETN-NODF means higher degree of nestedness in the export trade network structure with the country's industrial sector at its core, the more orderly export mechanism, and more stable relevant channels, which together help to increase the trade surplus and boost domestic economic growth. At the same time, export growth drives import growth, securing the source of raw materials for the normal functioning of a country's production system and the expansion of demands in its domestic consumer market, which in turn promotes the healthy development of the import trade network; as a result, ITN-NODF increases. However, compared to the export trade network which can be unstoppably expanded, the expansion of the import trade network is limited by the relatively homogenous source of raw materials, which is why ETN-NODF is higher in value than ITN-NODF.

\section{Conclusion}

The nested structure is a sustainable structural characteristic formed by species seeking ecosystem stability in the long-term development process, which has important implications for studying the functions and status of industrial sectors in the GVC network, as well as the national macro-industrial layout. Unlike previous studies that describe network characteristics through various network indicators, this paper measures and analyzes the ecological roles and functions of industrial sectors in the global production network from the perspective of the nested structure theory in ecology. This study thus builds a new theoretical analysis framework, and establishes, through econometric analysis, a bridge between the microstructure of local networks in the global production and countries' macroeconomic performance, directing countries to optimize the international and domestic industrial layout and participate in the international and domestic double cycle.

The vertical international division of labor and the continuous development of the global value chain have played an unprecedented role in promoting the economy and trade of all countries in the world. The dynamic exchange of resources across the world is 
also an important guarantee for the stable and orderly progress of the global value chain. Through static and dynamic analysis of the generalist degree of the sectors in the global production network, a phenomenon is found that most of the generalist sectors come from more developed economies which are in the most closely nested areas, so competition is fierce; Moreover, the sector's generalist degree has the characteristics of one to another. Due to the rapid increase in the generalist degree of China's manufacturing, the manufacturing and service in Japan and Taiwan have shown a downward trend, which paved the way for changes in the global supply chain pattern. These advanced economies and their related industrial sectors have also played a decisive role in maintaining the stability of the GVC network, which further reflects their important position in promoting the process of global economic integration. In addition, there is still a lot of room for optimization of the industrial layout on the global value chain. Encouraging specialist sectors to actively integrate into global trade is an effective way to improve the stability of the GVC network.

Under the premise of stable domestic economic operation, enhancing the stability of the international trading environment as well as active participation in the global value chain can significantly promote country's macroeconomic performance. Through the division of labor and resource exchange among countries, an economy can maximize its resource utilization efficiency and obtain the greatest economic benefits. Therefore, it is the most favorable choice for countries economic development to integrating in the global economic cycle.

Author Contributions: Conceptualization, J.-Q.R. and L.-Z.X.; methodology, L.-Z.X. and Y.H.; software, L.-Z.X.; validation, X.-L.D.; formal analysis, J.-Q.R. and L.-Z.X.; writing-original draft preparation, J.-Q.R. and L.-Z.X.; visualization, J.-Q.R. All authors have read and agreed to the published version of the manuscript.

Funding: This research was funded by National Natural Science Foundation of China (Grant No. 71971006), Humanities and Social Science Foundation of Ministry of Education of the People's Republic of China (Grant No. 19YJCGJW014).

Institutional Review Board Statement: Not applicable.

Informed Review Board Statement: Not applicable.

Data Availability Statement: We signed a confidentiality agreement with the transportation company who provided us the data used in this work. Hence the data will not be shared.

Conflicts of Interest: The authors declare no conflict of interest.

\section{Appendix A. Basic Information about Eora26}

Table A1. Countries' Names and Their Abbreviations of Eora26

\begin{tabular}{cccccc}
\hline No. & Abbr & Country & No. & Abbr & Country \\
\hline 1 & AFG & Afghanistan & 96 & LSO & Lesotho \\
2 & ALB & Albania & 97 & LBR & Liberia \\
3 & DZA & Algeria & 98 & LBY & Libya \\
4 & AND & Andorra & 99 & LIE & Liechtenstein \\
5 & AGO & Angola & 100 & LTU & Lithuania \\
6 & ATG & Antigua & 101 & LUX & Luxembourg \\
7 & ARG & Argentina & 102 & MAC & Macao SAR \\
8 & ARM & Armenia & 103 & MDG & Madagascar \\
9 & ABW & Aruba & 104 & MWI & Malawi \\
10 & AUS & Australia & 105 & MYS & Malaysia \\
11 & AUT & Austria & 106 & MDV & Maldives \\
12 & AZE & Azerbaijan & 107 & MLI & Mali \\
\hline
\end{tabular}




\begin{tabular}{|c|c|c|c|c|c|}
\hline No. & Abbr & Country & No. & Abbr & Country \\
\hline 13 & BHS & Bahamas & 108 & MLT & Malta \\
\hline 14 & BHR & Bahrain & 109 & MRT & Mauritania \\
\hline 15 & BGD & Bangladesh & 110 & MUS & Mauritius \\
\hline 16 & $\mathrm{BRB}$ & Barbados & 111 & MEX & Mexico \\
\hline 17 & BLR & Belarus & 112 & $\mathrm{MCO}$ & Monaco \\
\hline 18 & BEL & Belgium & 113 & MNG & Mongolia \\
\hline 19 & BLZ & Belize & 114 & MNE & Montenegro \\
\hline 20 & BEN & Benin & 115 & MAR & Morocco \\
\hline 21 & BMU & Bermuda & 116 & $\mathrm{MOZ}$ & Mozambique \\
\hline 22 & BTN & Bhutan & 117 & MMR & Myanmar \\
\hline 23 & BOL & Bolivia & 118 & NAM & Namibia \\
\hline 24 & $\mathrm{BIH}$ & Bosnia and Herzegovina & 119 & NPL & Nepal \\
\hline 25 & BWA & Botswana & 120 & NLD & Netherlands \\
\hline 26 & BRA & Brazil & 121 & ANT & Netherlands Antilles \\
\hline 27 & VGB & British Virgin Islands & 122 & NCL & New Caledonia \\
\hline 28 & BRN & Brunei & 123 & NZL & New Zealand \\
\hline 29 & BGR & Bulgaria & 124 & NIC & Nicaragua \\
\hline 30 & BFA & Burkina Faso & 125 & NER & Niger \\
\hline 31 & BDI & Burundi & 126 & $\mathrm{NGA}$ & Nigeria \\
\hline 32 & KHM & Cambodia & 127 & NOR & Norway \\
\hline 33 & CMR & Cameroon & 128 & PSE & Gaza Strip \\
\hline 34 & CAN & Canada & 129 & OMN & Oman \\
\hline 35 & $\mathrm{CPV}$ & Cape Verde & 130 & PAK & Pakistan \\
\hline 36 & CYM & Cayman Islands & 131 & PAN & Panama \\
\hline 37 & $\mathrm{CAF}$ & Central African Republic & 132 & PNG & Papua New Guinea \\
\hline 38 & TCD & Chad & 133 & PRY & Paraguay \\
\hline 39 & CHL & Chile & 134 & PER & Peru \\
\hline 40 & $\mathrm{CHN}$ & China & 135 & PHL & Philippines \\
\hline 41 & $\mathrm{COL}$ & Colombia & 136 & POL & Poland \\
\hline 42 & $\mathrm{COG}$ & Congo & 137 & PRT & Portugal \\
\hline 43 & CRI & Costa Rica & 138 & QAT & Qatar \\
\hline 44 & HRV & Croatia & 139 & KOR & South Korea \\
\hline 45 & CUB & Cuba & 140 & MDA & Moldova \\
\hline 46 & CYP & Cyprus & 141 & ROU & Romania \\
\hline 47 & CZE & Czech Republic & 142 & RUS & Russia \\
\hline 48 & CIV & Cote dIvoire & 143 & RWA & Rwanda \\
\hline 49 & PRK & North Korea & 144 & WSM & Samoa \\
\hline 50 & $\mathrm{COD}$ & DR Congo & 145 & SMR & San Marino \\
\hline 51 & DNK & Denmark & 146 & STP & Sao Tome and Principe \\
\hline 52 & DJI & Djibouti & 147 & SAU & Saudi Arabia \\
\hline 53 & DOM & Dominican Republic & 148 & SEN & Senegal \\
\hline 54 & ECU & Ecuador & 149 & SRB & Serbia \\
\hline
\end{tabular}




\begin{tabular}{|c|c|c|c|c|c|}
\hline No. & Abbr & Country & No. & Abbr & Country \\
\hline 55 & EGY & Egypt & 150 & SYC & Seychelles \\
\hline 56 & SLV & El Salvador & 151 & SLE & Sierra Leone \\
\hline 57 & ERI & Eritrea & 152 & SGP & Singapore \\
\hline 58 & EST & Estonia & 153 & SVK & Slovakia \\
\hline 59 & ETH & Ethiopia & 154 & SVN & Slovenia \\
\hline 60 & FJI & Fiji & 155 & SOM & Somalia \\
\hline 61 & FIN & Finland & 156 & ZAF & South Africa \\
\hline 62 & FRA & France & 157 & SDS & South Sudan \\
\hline 63 & PYF & French Polynesia & 158 & ESP & Spain \\
\hline 64 & GAB & Gabon & 159 & LKA & Sri Lanka \\
\hline 65 & GMB & Gambia & 160 & SUD & Sudan \\
\hline 66 & GEO & Georgia & 161 & SUR & Suriname \\
\hline 67 & DEU & Germany & 162 & SWZ & Swaziland \\
\hline 68 & GHA & Ghana & 163 & SWE & Sweden \\
\hline 69 & GRC & Greece & 164 & $\mathrm{CHE}$ & Switzerland \\
\hline 70 & GRL & Greenland & 165 & SYR & Syria \\
\hline 71 & GTM & Guatemala & 166 & TWN & Taiwan \\
\hline 72 & GIN & Guinea & 167 & TJK & Tajikistan \\
\hline 73 & GUY & Guyana & 168 & THA & Thailand \\
\hline 74 & HTI & Haiti & 169 & MKD & TFYR Macedonia \\
\hline 75 & HND & Honduras & 170 & TGO & Togo \\
\hline 76 & HKG & Hong Kong & 171 & TTO & Trinidad and Tobago \\
\hline 77 & HUN & Hungary & 172 & TUN & Tunisia \\
\hline 78 & ISL & Iceland & 173 & TUR & Turkey \\
\hline 79 & IND & India & 174 & TKM & Turkmenistan \\
\hline 80 & IDN & Indonesia & 175 & USR & Former USSR \\
\hline 81 & IRN & Iran & 176 & UGA & Uganda \\
\hline 82 & IRQ & Iraq & 177 & UKR & Ukraine \\
\hline 83 & IRL & Ireland & 178 & ARE & United Arab Emirates \\
\hline 84 & ISR & Israel & 179 & GBR & United Kingdom \\
\hline 85 & ITA & Italy & 180 & TZA & Tanzania \\
\hline 86 & JAM & Jamaica & 181 & USA & United States \\
\hline 87 & JPN & Japan & 182 & URY & Uruguay \\
\hline 88 & JOR & Jordan & 183 & UZB & Uzbekistan \\
\hline 89 & KAZ & Kazakhstan & 184 & VUT & Vanuatu \\
\hline 90 & KEN & Kenya & 185 & VEN & Venezuela \\
\hline 91 & KWT & Kuwait & 186 & VNM & Viet Nam \\
\hline 92 & KGZ & Kyrgyzstan & 187 & YEM & Yemen \\
\hline 93 & LAO & Laos & 188 & ZMB & Zambia \\
\hline 94 & LVA & Latvia & 189 & ZWE & Zimbabwe \\
\hline 95 & LBN & Lebanon & & & \\
\hline
\end{tabular}


Table A2. Eora26 Industry Code Description

\begin{tabular}{|c|c|c|}
\hline No. & Abbr & Industrial Sector \\
\hline 1 & S1 & Agriculture \\
\hline 2 & $\mathrm{~S} 2$ & Fishing \\
\hline 3 & $\mathrm{~S} 3$ & Mining and Quarrying \\
\hline 4 & S4 & Food \& Beverages \\
\hline 5 & S5 & Textiles and Wearing Apparel \\
\hline 6 & S6 & Wood and Paper \\
\hline 7 & S7 & Petroleum, Chemical and Non-Metallic Mineral Products \\
\hline 8 & S8 & Metal Products \\
\hline 9 & S9 & Electrical and Machinery \\
\hline 10 & $\mathrm{~S} 10$ & Transport Equipment \\
\hline 11 & S11 & Other Manufacturing \\
\hline 12 & $\mathrm{~S} 12$ & Recycling \\
\hline 13 & $\mathrm{~S} 13$ & Electricity, Gas and Water \\
\hline 14 & S14 & Construction \\
\hline 15 & $\mathrm{~S} 15$ & Maintenance and Repair \\
\hline 16 & S16 & Wholesale Trade \\
\hline 17 & S17 & Retail Trade \\
\hline 18 & $\mathrm{~S} 18$ & Hotels and Restaurants \\
\hline 19 & S19 & Transport \\
\hline 20 & S20 & Post and Telecommunications \\
\hline 21 & $\mathrm{~S} 21$ & Financial Intermediation and Business Activities \\
\hline 22 & $\mathrm{~S} 22$ & Public Administration \\
\hline 23 & $\mathrm{~S} 23$ & Education, Health and Other Services \\
\hline 24 & $\mathrm{~S} 24$ & Private Households \\
\hline 25 & $\mathrm{~S} 25$ & Others \\
\hline 26 & S26 & Re-export \& Re-import \\
\hline
\end{tabular}

Table A3. Four-Sector Categories in Eora26

\begin{tabular}{cc}
\hline Category & \multicolumn{1}{c}{ Sectors } \\
\hline $\begin{array}{c}\text { Agriculture } \\
(\mathrm{SC} 1)\end{array}$ & Agriculture; Fishing \\
\hline Mining & Mining and Quarrying \\
(SC2) & Food \& Beverages; Textiles and Wearing Apparel; Wood and Paper; \\
Manufacturing & Petroleum, Chemical and Non-Metallic Mineral Products; Metal \\
(SC3) & Products; Electrical and Machinery; Transport Equipment; Other \\
& Manufacturing; Recycling; Electricity, Gas and Water; Construction
\end{tabular}


Maintenance and Repair; Wholesale Trade; Retail Trade; Hotels

Services and Restraurants; Transport; Post and Telecommunications; Finan-

(SC4) cial Intermediation and Business Activities; Public Administration; Education, Health and Other Services; Private Households; Others;

Re-export \& Re-import

\section{Appendix B. Network Pruning}

The GIVCNBG model is a very dense weighted network, and there is a more or less value stream between each upstream sector and downstream sector. Therefore, before analyzing the nested structure, the network needs to be pruned to extract the backbone. While finding an effectual way to extract the backbone of weighted network, here come two questions. The first question is that the information content of network should be retained as much as possible with the decline of number of edges (Q1). In other word, the nature of network pruning is a trade-off between the number of retained edges and the gross of retained weights. The second question is that only the turely important edges linking nodes are worthy to be retained during downsizing the network (Q2). Sometimes, a weighted edge is numerically insignificant but functionally significant, and reckless deletion will result in a useless broken structure.

It is common in the weighted networks that, even at the local level defined by edges linking to a given node, only a few of those edges carry a disproportionate fraction of its strength, and the remaining ones take a very small percentage left. Enlightened by $\mathrm{H}-$ Index, the Pareto Principle, and the idea of Disparity Filter proposed by Vespignani, we present a novel heuristic algorithm to effectively prune the dense and weighted GIVCN model, which is named X-Index Filtering Algorithm (XIFA).

As we all known, Hirsch proposed that a scientist has index $h$ if $h$ of his or her $N_{p}$ papers have at least $h$ citations each and the other $\left(N_{p}-h\right)$ papers have $\leq h$ citations each. Obviously, this mixed quantitative index takes both quantity and quanlity of papers into account, which can be used as algorithm framework to solve the Q1 of this paper by weighing the pros and cons, namely the number and weights of edges. According to the Pareto principle, it makes sense that $80 \%$ of consequences come from $20 \%$ of the causes, asserting an unequal relationship between inputs and outputs. We hence assume that a minority of edges hold most weights in the network, which are regarded as the so-called important ones as mentioned in the Q2.

Therefore, the core idea of XIFA is as follows: An industrial sector has backward in$\operatorname{dex} \boldsymbol{x}\left(\boldsymbol{X} \boldsymbol{I}^{\boldsymbol{B}}\right) /$ forward index $\boldsymbol{x}\left(\boldsymbol{X I}^{\boldsymbol{F}}\right)$ if top $\boldsymbol{x}$ percent of its relations to all upstream/downstream sectors occupy at least $(\boldsymbol{1}-\boldsymbol{x} \%)$ of its total input/output amount of intermediate goods. Formula deduction and practical calculation process, as shown in Figure A1. According to the induction hypothesis, the X-index of a node is measured by the number of crucial edges with from big to small weights, and a smaller $X$-index value indicates that the edge-weight distribution of this node is more heterogeneous. In the directed networks, the XIFA is initiated by removing all in-degree edges of each node that are insufficient to show the local influence, and the pruning process is then repeated for the out-degree edges. It should be noted that some edges tended to be overlooked exist, for instance, certain edges are important in terms of in-degree but unimportant in terms of out-degree and vice versa, and one more rule is hence set, that is, the weighted edges that are worthy to be reserved in either of direction will stay.

A special sub-graph $G^{\prime}=(O, P, E, W)$ is extracted from GIVCNBG model based on XIFA, which is named GIVCNBG-FE model (FE refers to filtering edges). The left MRIO relations are different from the deleted ones depends on how heterogeneous the industrial sectors' inputs or outputs are all over the world. We can assume that around $20 \%$ of most important input or output relations of a given sector are supposed to cover $80 \%$ of its input or output amount of intermediate goods, which addresses the Q1 preferably. 
Table A4. The Procedure of Pruning GIVCN Model Based on XIFA

\begin{tabular}{|c|c|c|}
\hline Procedure & Column Deletion of Input Relations & Row Deletion of Output Relations \\
\hline Network & \multicolumn{2}{|c|}{$W=\left(w_{i j}\right)_{N \times N} i, j \in[1, N]$} \\
\hline Refactoring & $\begin{array}{c}\overleftarrow{w}_{1}=\operatorname{desecend}\left(w_{11}, w_{21}, \cdots, w_{N 1}\right)^{T} \\
\overleftarrow{w}_{2}=\operatorname{descend}\left(w_{12}, w_{22}, \cdots, w_{N 2}\right)^{T} \\
\cdots \\
\bar{w}_{N}=\operatorname{descend}\left(w_{1 N}, w_{2 N}, \cdots, w_{N N}\right)^{T} \\
\vec{W}=\left(\overleftarrow{w}_{1}, \overleftarrow{w}_{2}, \cdots, \bar{w}_{N}\right)=\left(\overleftarrow{w}_{s j}\right)_{N \times N} \\
s, j \in[1, N\end{array}$ & $\begin{array}{c}\vec{w}_{1}=\operatorname{desecend}\left(w_{11}, w_{12}, \cdots, w_{1 N}\right) \\
\vec{w}_{2}=\operatorname{descend}\left(w_{21}, w_{22}, \cdots, w_{2 N}\right) \\
\vec{w}_{N}=\operatorname{descend}\left(w_{N 1}, w_{N 2}, \cdots, w_{N N}\right) \\
\overleftarrow{W}=\left(\begin{array}{c}\vec{w}_{1} \\
\vec{w}_{2} \\
\cdots \\
\vec{w}_{N}\end{array}\right)=\left(\vec{w}_{i t}\right)_{N \times N} \\
i, t \in[1, N]\end{array}$ \\
\hline Conditions & $\begin{array}{c}\forall a_{1}, a_{2}, \cdots, a_{j} \in[1, N] \\
\left\{\begin{array}{c}\frac{\sum_{s=1}^{a_{j}} \overleftarrow{w}_{s j}}{\sum_{s=1}^{N} \overleftarrow{w}_{s j}} \geq 1-\frac{a_{j}}{N} \\
\frac{\sum_{s=1}^{a_{j}-1} \overleftarrow{w}_{s j}}{\sum_{s=1}^{N} \overleftarrow{w}_{s j}}<1-\frac{a_{j}-1}{N}\end{array}\right.\end{array}$ & $\begin{array}{c}\forall b_{1}, b_{2}, \cdots, b_{i} \in[1, N] \\
\left\{\begin{array}{c}\sum_{t=1}^{b_{i}} \vec{w}_{i t} \\
\sum_{t=1}^{N} \vec{w}_{i t} \\
\sum_{t=1}^{b_{i}-1} \vec{w}_{i t} \\
\frac{\sum_{t=1}^{N} \vec{w}_{i t}}{\sum_{i}}<1-\frac{b_{i}}{N}\end{array}\right. \\
\end{array}$ \\
\hline Definition & $\begin{array}{c}X I_{j}^{B}=\frac{a_{j}}{N} \\
X I^{B}=\left(X I_{j}^{B}\right)_{N \times 1}\end{array}$ & $\begin{array}{c}X I_{i}^{F}=\frac{b_{i}}{N} \\
X I^{F}=\left(X I_{i}^{F}\right)_{N \times 1}\end{array}$ \\
\hline Pruning & $\overleftarrow{w}_{i j}=\left\{\begin{array}{cc}w_{i j}, & w_{i j}=\overleftarrow{w}_{s j} \text { and } s \leq a_{j} \\
0, & \text { otherwise }\end{array}\right.$ & $\vec{w}_{i j}=\left\{\begin{array}{cc}w_{i j}, & w_{i j}=\vec{w}_{i t} \text { and } t \leq b_{i} \\
0, & \text { otherwise }\end{array}\right.$ \\
\hline Merging & & $\overleftrightarrow{w}_{i j}=\left\{\begin{array}{cc}w_{i j}, & \overleftrightarrow{w}_{i j} \neq 0 \text { or } \vec{w}_{i j} \neq 0 \\
0, & \text { otherwise }\end{array}\right.$ \\
\hline Result & & $\overleftrightarrow{W}=\left(\overleftrightarrow{w}_{i j}\right)_{N \times N}$ \\
\hline $\begin{array}{l}\text { Th } \\
\text { scope a } \\
\text { of the it } \\
\text { industr } \\
\text { weight } \\
\text { only ne } \\
\text { of conn } \\
\text { Frc } \\
\text { must be } \\
\text { input, } \mathrm{t} \\
\text { being tc } \\
\text { Mc } \\
\text { relation } \\
\text { method } \\
\text { Therefo } \\
\text { cally pa } \\
\text { High-D } \\
\text { studied }\end{array}$ & $\begin{array}{l}\text { XIFA algorithm is a mixed quantitative } \\
\text { d intensity of the influence of the indust } \\
\text { dustrial network according to the hetero } \\
\text { al sectors. From the perspective of compl } \\
\text { heterogeneity, a small number of connec } \\
\text { ded to keep, while for nodes with weak } \\
\text { ctions needed to keep are more, but not } \\
\text { m the perspective of industrial economic } \\
\text { considered. So a method of pruning se } \\
\text { en integrating, was adopted finally. This } \\
\text { o marginalized from GVC. } \\
\text { reover, overlapping two subnetworks vi } \\
\text { (rows) pruning process is only a partial } \\
\text { is still based on the relations with adjace } \\
\text { re, to solve Q1 and Q2 at the same time } \\
\text { rticipate in our other paper "Extracting th } \\
\text { mensional Multi-Region Input-Output } \\
\text { in this article, the GIVCNBG-FE model ha } \\
\text { rmation. }\end{array}$ & $\begin{array}{l}\text { ndicator, which takes into account the } \\
\text { al sector, extracting the main topology } \\
\text { eneity of input and output among the } \\
\text { networks, for nodes with strong edge } \\
\text { ons with extremely large weights are } \\
\text { dge weight heterogeneity, the number } \\
\text { ore than } 50 \% \text {. } \\
\text { the integrity of the global value chain } \\
\text { arately from the aspect of output and } \\
\text { revents certain industrial sectors from } \\
\text { input relations (columns) and output } \\
\text { lution to the Q2, because this pruning } \\
\text { nodes rather than global information. } \\
\text { ed to adopt a hybrid strategy, specifi- } \\
\text { Backbone of Global Value Chain from } \\
\text { twork". For the nested structure to be } \\
\text { extracted enough GVC network topol- }\end{array}$ \\
\hline
\end{tabular}


(a)

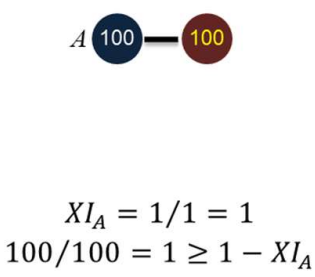

(b)

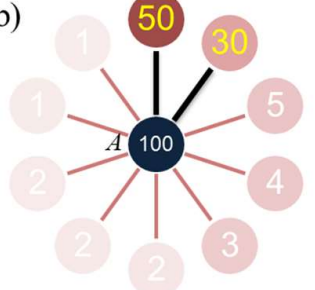

$X I_{A}=2 / 10=0.2$

$(50+30) / 100=0.8 \geq 1-X I_{A}$ (c)

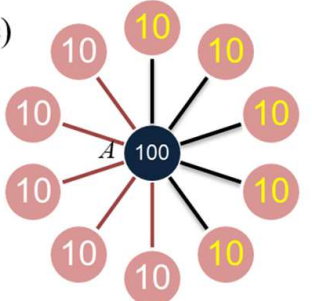

$X I_{A}=5 / 10=0.5$

$(10 \times 5) / 100=0.5 \geq 1-X I_{A}$

Figure A1. Three possible situations in the application of XIFA algorithm

\section{Appendix C. Complementary Econometric Analysis}

Table A5. Results of the Ridge Regression Model

\begin{tabular}{cccccc}
\hline Variables & Coef. & Robust Std. Err & $\mathbf{t}$ & $\mathbf{P}$ & $\mathbf{9 5 \%}$ Confidence Interval \\
\hline D-NODF & -9.49 & 2.64 & -3.60 & $0.000^{* * *}$ & {$[-14.67,-4.32]$} \\
P-NODF & 44.27 & 3.88 & 11.40 & $0.000^{* * *}$ & {$[36.65,51.90]$} \\
C-NODF & 21.03 & 6.88 & 3.06 & $0.002^{*}$ & {$[7.54,34.52]$} \\
Intercept & 71.97 & 180.36 & 0.40 & 0.690 & {$[-281.95,425.89]$} \\
Term & & & & \\
R2 (ad- & 0.411 & Root MSE & 867.68 & \\
justed) & & & & \\
\hline
\end{tabular}

Notes: There is basically no difference between the coefficient of ridge regression and the mixed regression with PCA. For example, the coefficients of D-NODF and P-NODF in ridge regression are -9.49 and 44.27 , and the mixed regression are $-9.63,48.99 * 0.8824=43.23$. Thus, the regression coefficients and related conclusions of the mixed regression model used in this paper are robust.

Table A6. Results of the FE Model

\begin{tabular}{cccccc}
\hline Variables & Coef. & Robust Std. Err & $\mathbf{t}$ & $\mathbf{P}$ & 95\% Confidence Interval \\
\hline D-NODF & 0.40 & 1.99 & 0.20 & 0.840 & {$[-3.52,4.33]$} \\
Comp. & 43.27 & 45.56 & 0.95 & 0.343 & {$[-46.62,133.17]$} \\
Intercept Term & -538.56 & 712.27 & -0.76 & 0.451 & {$[-1943.92,866.80]$} \\
\hline
\end{tabular}

Notes: All coefficients in the fixed effects model failed the test.

Table A7. Results of the LSDV Model

\begin{tabular}{cccccc}
\hline Variables & Coef. & Robust Std. Err & t & P & 95\% Confidence Interval \\
\hline D-NODF & 0.40 & 2.19 & 0.18 & 0.854 & {$[-3.91,4.72]$} \\
Comp. & 43.27 & 50.14 & 0.86 & 0.389 & {$[-55.65,142.20]$} \\
country & & & & & \\
\hline AFG & 346.87 & 353.84 & 0.98 & 0.328 & {$[-351.2987,1045.033]$} \\
AGO & 281.05 & 257.66 & 1.09 & 0.277 & {$[-227.3288,789.4262]$} \\
ALB & 216.71 & 218.33 & 0.99 & 0.322 & {$[-214.0759,647.4973]$} \\
AND & 236.70 & 238.52 & 0.99 & 0.322 & {$[-233.9195,707.3123]$}
\end{tabular}




\begin{tabular}{|c|c|c|c|c|c|}
\hline ARE & 422.05 & 276.65 & 1.53 & 0.129 & {$[-123.7993,967.9091]$} \\
\hline ARG & -346.32 & 749.44 & -0.46 & 0.645 & {$[-1825.031,1132.375]$} \\
\hline ARM & 214.61 & 231.28 & 0.93 & 0.355 & {$[-241.7304,670.9555]$} \\
\hline ATG & 202.95 & 188.93 & 1.07 & 0.284 & {$[-169.8275,575.7282]$} \\
\hline AUS & -477.86 & 1384.80 & -0.35 & 0.73 & {$[-3210.196,2254.469]$} \\
\hline AUT & -134.15 & 501.67 & -0.27 & 0.789 & {$[-1123.986,855.6903]$} \\
\hline AZE & 211.72 & 206.19 & 1.03 & 0.306 & {$[-195.0985,618.5441]$} \\
\hline BDI & 197.72 & 179.91 & 1.1 & 0.273 & {$[-157.2522,552.6847]$} \\
\hline BEL & -1179.98 & 1749.33 & -0.67 & 0.501 & {$[-4631.553,2271.592]$} \\
\hline BEN & 266.94 & 276.91 & 0.96 & 0.336 & {$[-279.4249,813.3128]$} \\
\hline BFA & 197.92 & 209.44 & 0.94 & 0.346 & {$[-215.324,611.1616]$} \\
\hline BGD & 463.47 & 441.16 & 1.05 & 0.295 & {$[-406.9706,1333.907]$} \\
\hline BGR & 322.55 & 330.76 & 0.98 & 0.331 & {$[-330.0761,975.1704]$} \\
\hline BHR & 321.21 & 341.12 & 0.94 & 0.348 & {$[-351.8472,994.2654]$} \\
\hline BHS & 263.53 & 275.51 & 0.96 & 0.34 & {$[-280.0784,807.1395]$} \\
\hline BIH & 303.62 & 310.98 & 0.98 & 0.33 & {$[-309.9727,917.2204]$} \\
\hline BLR & 109.25 & 102.04 & 1.07 & 0.286 & {$[-92.07386,310.582]$} \\
\hline BLZ & 142.7 & 156.80 & 0.91 & 0.364 & {$[-166.6857,452.0805]$} \\
\hline BMU & 163.46 & 161.68 & 1.01 & 0.313 & {$[-155.5533,482.4662]$} \\
\hline BOL & 80.53 & 84.62 & 0.95 & 0.343 & {$[-86.4349,247.4872]$} \\
\hline BRA & 527.65 & 715.03 & 0.74 & 0.462 & {$[-883.1721,1938.471]$} \\
\hline BRB & 282.83 & 291.34 & 0.97 & 0.333 & {$[-292.0029,857.6546]$} \\
\hline $\mathrm{BRN}$ & 334.04 & 351.24 & 0.95 & 0.343 & {$[-358.9823,1027.066]$} \\
\hline BTN & 79.27 & 88.60 & 0.89 & 0.372 & {$[-95.53579,254.075]$} \\
\hline BWA & 285.04 & 305.34 & 0.93 & 0.352 & {$[-317.4236,887.4988]$} \\
\hline CAF & 265.57 & 260.87 & 1.02 & 0.31 & {$[-249.161,780.2916]$} \\
\hline CAN & 770.19 & 341.90 & 2.25 & $0.025^{*}$ & {$[95.58298,1444.791]$} \\
\hline CHE & -909.9 & 1534.75 & -0.59 & 0.554 & {$[-3938.092,2118.301]$} \\
\hline $\mathrm{CHL}$ & -60.5 & 228.66 & -0.26 & 0.792 & {$[-511.6715,390.6751]$} \\
\hline $\mathrm{CHN}$ & 1503.19 & 2459.50 & 0.61 & 0.542 & {$[-3349.617,6355.998]$} \\
\hline $\mathrm{CIV}$ & 346.24 & 367.63 & 0.94 & 0.348 & {$[-379.13,1071.614]$} \\
\hline CMR & 360.41 & 378.99 & 0.95 & 0.343 & {$[-387.3771,1108.196]$} \\
\hline COD & 265.26 & 265.10 & 1 & 0.318 & {$[-257.8036,788.316]$} \\
\hline $\mathrm{COG}$ & 290.82 & 307.71 & 0.95 & 0.346 & {$[-316.319,897.9642]$} \\
\hline $\mathrm{COL}$ & 81.02 & 76.04 & 1.07 & 0.288 & {$[-69.00603,231.0458]$} \\
\hline $\mathrm{CPV}$ & 219 & 208.95 & 1.05 & 0.296 & {$[-193.2711,631.2752]$} \\
\hline CRI & 390.24 & 414.36 & 0.94 & 0.348 & {$[-427.3227,1207.812]$} \\
\hline CUB & 381.23 & 369.91 & 1.03 & 0.304 & {$[-348.6375,1111.096]$} \\
\hline CYP & 342.62 & 366.80 & 0.93 & 0.352 & {$[-381.1153,1066.35]$} \\
\hline CZE & -172.23 & 317.34 & -0.54 & 0.588 & {$[-798.369,453.9041]$} \\
\hline DEU & 198.25 & 2855.59 & 0.07 & 0.945 & {$[-5436.072,5832.577]$} \\
\hline DJI & 163.01 & 138.96 & 1.17 & 0.242 & {$[-111.1765,437.1888]$} \\
\hline DNK & -703.72 & 1088.11 & -0.65 & 0.519 & {$[-2850.657,1443.218]$} \\
\hline
\end{tabular}




\begin{tabular}{|c|c|c|c|c|c|}
\hline DOM & 416.84 & 427.58 & 0.97 & 0.331 & {$[-426.8171,1260.502]$} \\
\hline DZA & 408.18 & 350.16 & 1.17 & 0.245 & {$[-282.7166,1099.085]$} \\
\hline $\mathrm{ECU}$ & -118.3 & 175.10 & -0.68 & 0.5 & {$[-463.7915,227.1998]$} \\
\hline EGY & 511.76 & 410.13 & 1.25 & 0.214 & {$[-297.4581,1320.971]$} \\
\hline ERI & 235.58 & 222.08 & 1.06 & 0.29 & {$[-202.6103,673.7649]$} \\
\hline ESP & -609.87 & 1790.20 & -0.34 & 0.734 & {$[-4142.082,2922.346]$} \\
\hline EST & -48.19 & 69.35 & -0.69 & 0.488 & {$[-185.0211,88.64208]$} \\
\hline ETH & -107.18 & 134.83 & -0.79 & 0.428 & {$[-373.2024,158.8407]$} \\
\hline FIN & -20.37 & 245.53 & -0.08 & 0.934 & {$[-504.8219,464.0865]$} \\
\hline FJI & 276.83 & 299.98 & 0.92 & 0.357 & {$[-315.0676,868.72]$} \\
\hline FRA & -1.51 & 2245.24 & 0 & 0.999 & {$[-4431.562,4428.534]$} \\
\hline GAB & 314.42 & 332.34 & 0.95 & 0.345 & {$[-341.3062,970.1512]$} \\
\hline GBR & -1022.55 & 3512.17 & -0.29 & 0.771 & {$[-7952.356,5907.252]$} \\
\hline GEO & -178.73 & 200.24 & -0.89 & 0.373 & {$[-573.8264,216.3583]$} \\
\hline GHA & 323.03 & 336.75 & 0.96 & 0.339 & {$[-341.3976,987.4673]$} \\
\hline GIN & 264.45 & 280.28 & 0.94 & 0.347 & {$[-288.5671,817.4742]$} \\
\hline GMB & 203.94 & 205.10 & 0.99 & 0.321 & {$[-200.7466,608.6262]$} \\
\hline GRC & 100.46 & 91.75 & 1.09 & 0.275 & {$[-80.57459,281.495]$} \\
\hline GRL & 375.57 & 432.99 & 0.87 & 0.387 & {$[-478.7589,1229.897]$} \\
\hline GTM & 400.99 & 420.56 & 0.95 & 0.342 & {$[-428.8063,1230.781]$} \\
\hline GUY & 403.69 & 444.55 & 0.91 & 0.365 & {$[-473.4424,1280.816]$} \\
\hline HKG & -172.88 & 417.98 & -0.41 & 0.68 & {$[-997.5889,651.824]$} \\
\hline HND & 351.7 & 384.12 & 0.92 & 0.361 & {$[-406.2073,1109.612]$} \\
\hline HRV & 393.84 & 411.64 & 0.96 & 0.34 & {$[-418.3654,1206.055]$} \\
\hline HTI & 322.38 & 338.26 & 0.95 & 0.342 & {$[-345.0331,989.8003]$} \\
\hline HUN & -39.7 & 165.92 & -0.24 & 0.811 & {$[-367.0765,287.6826]$} \\
\hline IDN & -204.47 & 695.67 & -0.29 & 0.769 & {$[-1577.078,1168.141]$} \\
\hline IND & -405.95 & 1554.43 & -0.26 & 0.794 & {$[-3472.961,2661.06]$} \\
\hline IRL & 61.82 & 107.64 & 0.57 & 0.566 & {$[-150.5622,274.2033]$} \\
\hline IRN & -367.70 & 704.14 & -0.52 & 0.602 & {$[-1757.034,1021.625]$} \\
\hline IRQ & 287.09 & 163.82 & 1.75 & 0.081 & {$[-36.13326,610.32]$} \\
\hline ISL & 336.34 & 362.54 & 0.93 & 0.355 & {$[-378.9751,1051.662]$} \\
\hline ISR & -403.11 & 647.93 & -0.62 & 0.535 & {$[-1681.534,875.3045]$} \\
\hline ITA & -358.7 & 2247.07 & -0.16 & 0.873 & {$[-4792.36,4074.952]$} \\
\hline JAM & 351.8 & 378.13 & 0.93 & 0.353 & {$[-394.2818,1097.891]$} \\
\hline JOR & 325.8 & 359.43 & 0.91 & 0.366 & {$[-383.3841,1034.987]$} \\
\hline JPN & 2047.56 & 3094.29 & 0.66 & 0.509 & {$[-4057.734,8152.856]$} \\
\hline KAZ & -244.62 & 362.13 & -0.68 & 0.5 & {$[-959.1294,469.8803]$} \\
\hline KEN & -197.97 & 244.35 & -0.81 & 0.419 & {$[-680.0901,284.1591]$} \\
\hline KGZ & -455.86 & 512.61 & -0.89 & 0.375 & {$[-1467.283,555.5592]$} \\
\hline KHM & 289.57 & 316.28 & 0.92 & 0.361 & {$[-334.4798,913.6205]$} \\
\hline KOR & -313.24 & 1286.85 & -0.24 & 0.808 & {$[-2852.31,2225.822]$} \\
\hline KWT & -154.41 & 235.90 & -0.65 & 0.514 & {$[-619.8692,311.0498]$} \\
\hline
\end{tabular}




\begin{tabular}{|c|c|c|c|c|c|}
\hline LAO & 270.07 & 289.50 & 0.93 & 0.352 & {$[-301.147,841.2839]$} \\
\hline LBN & 323.88 & 326.75 & 0.99 & 0.323 & {$[-320.815,968.5826]$} \\
\hline LBR & 184.38 & 192.94 & 0.96 & 0.341 & {$[-196.318,565.0694]$} \\
\hline LBY & 365.12 & 357.11 & 1.02 & 0.308 & {$[-339.4948,1069.737]$} \\
\hline LIE & 302.74 & 309.76 & 0.98 & 0.33 & {$[-308.4337,913.9225]$} \\
\hline LKA & 355.78 & 375.62 & 0.95 & 0.345 & {$[-385.3557,1096.923]$} \\
\hline LSO & 134.13 & 131.54 & 1.02 & 0.309 & {$[-125.4121,393.6786]$} \\
\hline LTU & -77.57 & 124.47 & -0.62 & 0.534 & {$[-323.162,168.0136]$} \\
\hline LUX & 3.05 & 33.70 & 0.09 & 0.928 & {$[-63.45578,69.54905]$} \\
\hline LVA & -70.4 & 97.66 & -0.72 & 0.472 & {$[-263.0863,122.2896]$} \\
\hline MAC & 235.37 & 247.68 & 0.95 & 0.343 & {$[-253.3254,724.0649]$} \\
\hline MAR & 426.86 & 415.58 & 1.03 & 0.306 & {$[-393.1085,1246.832]$} \\
\hline $\mathrm{MCO}$ & 228.67 & 228.95 & 1 & 0.319 & {$[-223.0632,680.4089]$} \\
\hline MDA & 26.78 & 37.72 & 0.71 & 0.479 & {$[-47.63299,101.1987]$} \\
\hline MDG & 293.64 & 318.76 & 0.92 & 0.358 & {$[-335.2989,922.5689]$} \\
\hline MDV & 88.83 & 87.04 & 1.02 & 0.309 & {$[-82.90518,260.5718]$} \\
\hline MEX & 374.19 & 398.69 & 0.94 & 0.349 & {$[-412.467,1160.84]$} \\
\hline MKD & -157.69 & 179.44 & -0.88 & 0.381 & {$[-511.7428,196.361]$} \\
\hline MLI & 275.04 & 271.87 & 1.01 & 0.313 & {$[-261.3773,811.4663]$} \\
\hline MLT & -125.21 & 149.46 & -0.84 & 0.403 & {$[-420.1182,169.6895]$} \\
\hline MMR & 456.09 & 479.59 & 0.95 & 0.343 & {$[-490.168,1402.357]$} \\
\hline MNE & 32.86 & 22.77 & 1.44 & 0.151 & {$[-12.06697,77.78323]$} \\
\hline $\mathrm{MNG}$ & 209.38 & 216.84 & 0.97 & 0.336 & {$[-218.4693,637.2248]$} \\
\hline $\mathrm{MOZ}$ & 277.65 & 287.27 & 0.97 & 0.335 & {$[-289.1506,844.4498]$} \\
\hline MRT & 136.57 & 144.52 & 0.94 & 0.346 & {$[-148.5807,421.7112]$} \\
\hline MUS & -221.78 & 246.34 & -0.9 & 0.369 & {$[-707.8259,264.269]$} \\
\hline MWI & 265.54 & 286.68 & 0.93 & 0.356 & {$[-300.1154,831.1903]$} \\
\hline MYS & -432.16 & 665.46 & -0.65 & 0.517 & {$[-1745.172,880.8547]$} \\
\hline NAM & 282.94 & 314.23 & 0.9 & 0.369 & {$[-337.0612,902.9311]$} \\
\hline NCL & 285.79 & 312.88 & 0.91 & 0.362 & {$[-331.5583,903.1301]$} \\
\hline NER & 211.67 & 211.31 & 1 & 0.318 & {$[-205.2679,628.5985]$} \\
\hline NGA & 462.42 & 328.72 & 1.41 & 0.161 & {$[-186.1661,1111.009]$} \\
\hline $\mathrm{NIC}$ & 298.84 & 323.29 & 0.92 & 0.357 & {$[-339.0496,936.7254]$} \\
\hline NLD & -1257.85 & 2128.45 & -0.59 & 0.555 & {$[-5457.455,2941.764]$} \\
\hline NOR & 171.77 & 144.10 & 1.19 & 0.235 & {$[-112.5632,456.0975]$} \\
\hline NPL & 322.12 & 342.61 & 0.94 & 0.348 & {$[-353.8727,998.1114]$} \\
\hline NZL & -324.92 & 491.89 & -0.66 & 0.51 & {$[-1295.46,645.6192]$} \\
\hline OMN & 306.8 & 306.43 & 1 & 0.318 & {$[-297.7998,911.4071]$} \\
\hline PAK & 493.49 & 426.25 & 1.16 & 0.248 & {$[-347.5393,1334.529]$} \\
\hline PAN & 366.84 & 392.24 & 0.94 & 0.351 & {$[-407.0808,1140.766]$} \\
\hline PER & 271.73 & 222.84 & 1.22 & 0.224 & {$[-167.9554,711.4218]$} \\
\hline PHL & -104.64 & 262.64 & -0.4 & 0.691 & {$[-622.8616,413.5793]$} \\
\hline PNG & 297.34 & 316.28 & 0.94 & 0.348 & {$[-326.6992,921.381]$} \\
\hline
\end{tabular}




\begin{tabular}{|c|c|c|c|c|c|}
\hline POL & 297.22 & 20.63 & 14.4 & $0 * * *$ & {$[256.5053,337.9304]$} \\
\hline PRT & -41.92 & 222.84 & -0.19 & 0.851 & {$[-481.6021,397.7661]$} \\
\hline PRY & -60.38 & 68.79 & -0.88 & 0.381 & {$[-196.1178,75.3495]$} \\
\hline PSE & 250.98 & 256.15 & 0.98 & 0.328 & {$[-254.4312,756.3853]$} \\
\hline PYF & 300.49 & 308.45 & 0.97 & 0.331 & {$[-308.1146,909.092]$} \\
\hline QAT & 207.47 & 166.47 & 1.25 & 0.214 & {$[-120.9961,535.9267]$} \\
\hline ROU & -172.6 & 299.78 & -0.58 & 0.565 & {$[-764.0896,418.8857]$} \\
\hline RUS & 55.24 & 861.24 & 0.06 & 0.949 & {$[-1644.06,1754.53]$} \\
\hline RWA & 205.69 & 207.25 & 0.99 & 0.322 & {$[-203.2454,614.611]$} \\
\hline SAU & 678.99 & 400.19 & 1.7 & 0.091 & {$[-110.6093,1468.596]$} \\
\hline SDN & 678.37 & 630.08 & 1.08 & 0.283 & {$[-564.8316,1921.575]$} \\
\hline SEN & 213.10 & 229.29 & 0.93 & 0.354 & {$[-239.313,665.5046]$} \\
\hline SGP & -1055.88 & 1389.32 & -0.76 & 0.448 & {$[-3797.131,1685.373]$} \\
\hline SLE & 236.47 & 236.93 & 1 & 0.32 & {$[-231.0028,703.9444]$} \\
\hline SLV & 371.88 & 399.40 & 0.93 & 0.353 & {$[-416.1667,1159.925]$} \\
\hline SMR & 211.90 & 195.89 & 1.08 & 0.281 & {$[-174.6041,598.398]$} \\
\hline SOM & 300.16 & 297.33 & 1.01 & 0.314 & {$[-286.5072,886.8234]$} \\
\hline SRB & 94.44 & 55.08 & 1.71 & 0.088 & {$[-14.23795,203.1249]$} \\
\hline SSD & 400.82 & 407.84 & 0.98 & 0.327 & {$[-403.8719,1205.521]$} \\
\hline STP & 193.51 & 198.63 & 0.97 & 0.331 & {$[-198.4036,585.4259]$} \\
\hline SUR & 243.73 & 262.98 & 0.93 & 0.355 & {$[-275.149,762.6014]$} \\
\hline SVK & -247.02 & 326.19 & -0.76 & 0.45 & {$[-890.6272,396.5884]$} \\
\hline SVN & 19.56 & 13.68 & 1.43 & 0.155 & {$[-7.434995,46.55195]$} \\
\hline SWE & -393.60 & 866.62 & -0.45 & 0.65 & {$[-2103.527,1316.32]$} \\
\hline SWZ & 242.6 & 251.98 & 0.96 & 0.337 & {$[-254.5818,739.7901]$} \\
\hline SYC & 132.13 & 125.70 & 1.05 & 0.295 & {$[-115.8824,380.1409]$} \\
\hline SYR & 359.9 & 377.63 & 0.95 & 0.342 & {$[-385.2012,1104.996]$} \\
\hline TCD & 188.54 & 157.18 & 1.2 & 0.232 & {$[-121.5861,498.6678]$} \\
\hline TGO & 238.09 & 240.84 & 0.99 & 0.324 & {$[-237.107,713.2928]$} \\
\hline THA & -888.23 & 1271.91 & -0.7 & 0.486 & {$[-3397.813,1621.363]$} \\
\hline TJK & 244.53 & 256.35 & 0.95 & 0.341 & {$[-261.2624,750.32]$} \\
\hline TKM & 241.53 & 249.09 & 0.97 & 0.334 & {$[-249.9408,732.9929]$} \\
\hline TTO & 233.84 & 258.47 & 0.9 & 0.367 & {$[-276.1362,743.8105]$} \\
\hline TUN & 390.26 & 415.38 & 0.94 & 0.349 & {$[-429.3194,1209.847]$} \\
\hline TUR & 151.52 & 355.53 & 0.43 & 0.67 & {$[-549.9788,853.0178]$} \\
\hline TZA & 363.15 & 384.23 & 0.95 & 0.346 & {$[-394.9798,1121.274]$} \\
\hline UGA & 338.52 & 352.60 & 0.96 & 0.338 & {$[-357.1915,1034.23]$} \\
\hline UKR & -625.16 & 818.54 & -0.76 & 0.446 & {$[-2240.213,989.8846]$} \\
\hline URY & -251.19 & 310.16 & -0.81 & 0.419 & {$[-863.1708,360.7852]$} \\
\hline USA & 8620.85 & 3545.36 & 2.43 & $0.016^{*}$ & {$[1625.561,15616.13]$} \\
\hline UZB & -500.93 & 603.00 & -0.83 & 0.407 & {$[-1690.688,688.8321]$} \\
\hline VEN & -229.32 & 437.64 & -0.52 & 0.601 & {$[-1092.822,634.1773]$} \\
\hline VNM & -357.61 & 489.28 & -0.73 & 0.466 & {$[-1323.01,607.7872]$} \\
\hline
\end{tabular}




\begin{tabular}{cccccc} 
VUT & 180.37 & 171.08 & 1.05 & 0.293 & {$[-157.189,517.9312]$} \\
WSM & 146.34 & 140.63 & 1.04 & 0.299 & {$[-131.1335,423.8183]$} \\
YEM & 343.20 & 357.33 & 0.96 & 0.338 & {$[-361.8306,1048.234]$} \\
ZAF & -490.76 & 832.22 & -0.59 & 0.556 & {$[-2132.81,1151.288]$} \\
ZMB & 194.33 & 185.64 & 1.05 & 0.297 & {$[-171.9579,560.6236]$} \\
ZWE & 272.31 & 291.27 & 0.93 & 0.351 & {$[-302.3891,847.0155]$} \\
\hline cons & -701.87 & 663.58 & -1.06 & 0.292 & {$[-2011.17,607.42]$} \\
\hline
\end{tabular}

Notes: The intercept term of each country basically fails the test, which further shows that the individual effect between countries is not significant, and the mixed regression model is thus better.

Table A8. Results of the RE Model

\begin{tabular}{cccccc}
\hline Variables & Coef. & Robust Std. Err & $\mathbf{Z}$ & $\mathbf{P}$ & $\mathbf{9 5 \%}$ Confidence Interval \\
\hline D-NODF & -1.89 & 1.33 & -1.42 & 0.156 & {$[-4.50,0.72]$} \\
\hline Comp. & 46.55 & 13.81 & 3.37 & $0.001^{* *}$ & {$[19.49,73.61]$} \\
\hline Intercept Term & -430.93 & 188.57 & -2.29 & $0.022^{*}$ & {$[-800.53,-61.33]$} \\
\hline
\end{tabular}

Notes: C-NODF fails the test, indicating that the fitting effect of random effects is not good.

\section{References}

1. Thebault E, Fontaine C. Stability of Ecological Communities and the Architecture of Mutualistic and Trophic Networks[J]. Science, 2010, 329(5993):853-856.

2. Mariani M S, Ren Z M, Bascompte J, et al. Nestedness in complex networks: Observation, emergence, and implications[J]. Physics Reports, 2019, 813: 1-90. https://doi.org/10.1016/j.physrep.2019.04.001.

3. Suweis S, Simini F, Banavar J R, et al. Emergence of structural and dynamical properties of ecological mutualistic networks[J]. Nature, 2013, 500(7463):449-52.

4. Manville R H. Darlington, P J. Zoogeography: the geographical distribution of animals[M]. John Wiley \& Sons, 1957. https://doi.org/10.2307/1440574.

5. Patterson B D, Atmar W. Nested subsets and the structure of insular mammalian faunas and archipelagos[J]. Biological Journal of the Linnean Society, 1986, 28: 65-82. https://doi.org/ 10.1111/j.1095-8312.1986.tb01749.x.

6. Bascompte, J. The nested assembly of plant-animal mutualistic networks[J]. Proceedings of the National Academy of Sciences of the United States of America, 2003, 100(16):9383-9387. https://doi.org/10.1073/pnas.1633576100.

7. Leontief W W. The Structure of the U.S. Economy[J]. Scientific American, 1965, 212(4):25-35. https://doi.org/10.1038/scientificamerican0465-25.

8. Soramki K, Bech M L, Arnold J, et al. The topology of interbank payment flows[J]. Physica A: Statal Mechanics and its Applications, 2007, 379: 317-333. https://doi.org/10.1016/j.physa.2006.11.093.

9. Saavedra S, Reed-Tsochas F, Uzzi B. A simple model of bipartite cooperation for ecological and organizational networks[J]. Nature, 2009, 457(7228):463-466. https://doi.org/10.1038/nature07532.

10. Hernández Laura, Annick V, Saba Stéphanie, et al. Trust or robustness? An ecological approach to the study of auction and bilateral markets[J]. PLoS ONE, 2018, 13(5): e0196206. https://doi.org/10.1371/journal.pone.0196206.

11. Tacchella A, Cristelli M, Caldarelli G, et al. A New Metrics for Countries' Fitness and Products' Complexity[J]. Scientific Reports, 2012. https://doi.org/10.1038/srep00723.

12. Bustos S, Gomez C, Hausmann R, Hidalgo C A. The Dynamics of Nestedness Predicts the Evolution of Industrial Ecosystems. PLoS ONE, 2012, 7(11): e49393. https://doi.org/10.1371/journal.pone.0049393.

13. Alves L G A, Mangioni G, Cingolani I, et al. The nested structural organization of the worldwide trade multi-layer network[J]. Scientific Reports, 2018. https://doi.org/10.1038/s41598-019-39340-w.

14. Brehm C, Layton A. Nestedness in eco-industrial parks: exploring linkage distribution to promote sustainable industrial growth[J]. Journal of Industrial Ecology, 2020. https://doi.org/10.1111/jiec.13057.

15. JinTun Z. Quantitative ecology [M]. BeiJing: Science Press, 2018.

16. Benedictis L D, Tajoli L. The World Trade Network[J]. World Economy, 2011, 34(8):1417-1454. https://doi.org/10.1111/j.1467-9701.2011.01360.x.

17. Timmer M P, Los B, Stehrer R, de Vries G J D. An Anatomy of the Global Trade Slowdown based on the WIOD 2016 Release [R]. GGDC research memorandum number 162, University of Groningen, 2016.

18. Koopman R, Powers W, Wang Z, et al. Give credit where credit is due: Tracing value added in global production chains [R]. NBER Working Paper, 2010. 
19. Wang Z, Wei S J, Yu X, et al. Measures of participation in global value chains and global business cycles [J]. NBER Working Papers, 23222, 2017.

20. Guan J, Xu X Y, Wu S, Xing L Z. Measurement and simulation of the relatively competitive advantages and weaknesses between economies based on bipartite graph theory. PLoS ONE, 2018, 13(5): e0197575. https://doi.org/10.1371/journal.pone.0197575.

21. Jun Guan, Jiaqi Ren, Lizhi Xing. Measuring the Nestedness of Global Production System Based on Bipartite Network [CA]. The 9th International Conference on Complex Networks and Their Application (Complex Network 2020), Madrid, Spain, December 1-3, 2020, Complex Networks \& Their Applications IX: 547-558. https://doi.org/10.1007/978-3-030-65351-4_44.

22. Lizhi Xing, Yu Han. Extracting the Backbone of Global Value Chain from High-Dimensional Inter-Country Input-Output Network [CA]. The 9th International Conference on Complex Networks and Their Application (Complex Network 2020), Madrid, Spain, December 1-3, 2020, Complex Networks \& Their Applications IX: 559-570.

23. Hirsch J E. An Index to Quantify an Individual's Scientific Research Output[J]. Proceedings of the National Academy of Sciences of the United States of America, 2005,102(46): 16569-16572. https://doi.org/10.1073/pnas.0507655102.

24. Serrano M A, Boguna M, Vespignani A. Extracting the multiscale backbone of complex weighted networks[J]. Proceedings of the National Academy of Sciences of the United States of America, 2009, 106(16):6483-6488. https://doi.org/10.1073/pnas.0808904106.

25. Rohr R P, Saavedra S, Bascompte J. On the structural stability of mutualistic systems[J]. Science, 2014, 345(6195):12534971253497. https://doi.org/10.1126/science.1253497.

26. Ugo Bastolla, Miguel A F, Alberto Pascual-García, et al. The architecture of mutualistic networks minimizes competition and increases biodiversity[J]. Nature: International weekly journal of science, 2009, 458(7241): 1018 -U91. https://doi.org/10.1038/nature07950.

27. Atmar W, Patterson B D. The measure of order and disorder in the distribution of species in fragmented habitat[J]. Oecologia, 1993, 96(3):373-382. https://doi.org/10.1007/BF00317508.

28. Miguel A. Rodríguez-Gironés, Luis Santamaría. A new algorithm to calculate the nestedness temperature of presenceabsence matrices[J]. Journal of Biogeography, 2010, 33(5): 924-935. https://doi.org/10.1111/j.1365-2699.2006.01444.x.

29. Almeida-Neto, $\mathrm{M}$, et al. A consistent metric for nestedness analysis in ecological systems: reconciling concept and measurement[J]. Oikos, 2008, 117(8): 1227-1239. https://doi.org/10.1111/j.0030-1299.2008.16644.x.

30. Wang Z. The global supply chain revolution in the post-epidemic era-the road to smart and resilient transformation [R]. Institute of Global Value Chain, University of International Business and Economics, 2020.

31. Zuo L C. The Strategic Wishes and Outlook of India's Manufacturing Industry Development[J]. South Asian Studies Quarterly, 2006: 14-17+4.

32. Prebisch R. The Economic Development of Latin America and its Principal[J]. American Economic Review, 1958 : 201. https://doi.org/10.2307/211313.

33. Baran P A. The Political Economy of Growth[M]. Monthly Review Press, 1957. https://doi.org/10.14452/MR-009-01-195705_3.

34. Frank A G. Capitalism and Underdevelopment in Latin America: Historical Studies of Chile and Brazil[M]. Monthly Review Press, 1969. https://doi.org/10.2307/2229500.

35. Amin S. Unequal Development: Social Formations at the Periphery of the Capitalist System[M]. Branch Line, 1976. https://doi.org/10.1177/030981687700300107.

36. Ciampaglia G L, Shiralkar P, Rocha L M, et al. Computational Fact Checking from Knowledge Networks[J]. Plos One, 2015, 10(10): e0141938. https://doi.org/10.1371/journal.pone.0128193. 